\title{
Nuevas evidencias del magmatismo asociado con el sistema geotérmico de Paipa, Boyacá, Colombia
}

\author{
Jesús Bernardo Rueda-Gutiérrez ${ }^{1 *}$ \\ Forma de citar: Rueda-Gutiérrez, J.B. (2020). Nuevas evidencias del magmatismo asociado \\ con el sistema geotérmico de Paipa, Boyacá, Colombia. Boletín de Geología, 42(3), 51-79. \\ https://doi.org/10.18273/revbol.v42n3-2020002
}

\begin{abstract}
Resumen
Fueron caracterizados los cuerpos dómicos del área geotérmica de Paipa, Departamento de Boyacá, separados en tres sectores. El Alto Los Volcanes comprende dos zonas donde son evidentes cuatro elevaciones que sobresalen de la superficie, con afloramientos fuertemente meteorizados, pero con evidentes texturas volcánicas demarcadas por grandes fenocristales de feldespatos potásicos dentro de una masa fundamental blanca. En Quebrada Honda se presenta una estructura dómica donde dominan los megacristales de feldespatos, mientras que el Alto Los Godos comprende cinco cuerpos dómicos con textura porfirítica y cristales de feldespatos. Petrográficamente presentan características similares en los tres sectores, con presencia feldespato potásico (sanidina/anortoclasas) + plagioclasa (albita) + anfíbol (hornblenda) + biotita. Cantidades variables de caolinita se muestran especialmente para algunos reemplazamientos de feldespatos y como venas. Químicamente los cuerpos se clasifican como riolitas/traquidacitas, con firma química de magmas subalcalinos de serie calcoalcalina rica en potasio típico de arcos volcánicos. Los REE muestran un enriquecimiento de las LREE con promedios de $(\mathrm{La} / \mathrm{Sm})_{\mathrm{N}}$ entre 5,944 y 14,726 respecto a las HREE con valores de $(\mathrm{Gd} / \mathrm{Yb})_{\mathrm{N}}$ entre 0,626 y 2,318 y con una importante anomalía positiva de $\mathrm{Eu}_{\mathrm{N}} /\left(\mathrm{Sm}_{\mathrm{N}}{ }^{*} \mathrm{Gd}_{\mathrm{N}}\right)^{1 / 2}$ entre 1,321 y 3,84. Dataciones Ar-Ar en anfíbol y feldespatos, dieron como resultado para el sector del Alto Los Volcanes y Quebrada Honda edades de 1,76 y 1,8 Ma respectivamente, por otro lado, para el Alto Los Godos se registraron para tres domos edades de 2,8, 2,7 y 2,6 Ma. Evidencias de cuerpos intrusivos sin aflorar fueron identificadas al norte y sur del área de trabajo a partir de la geomorfología y resultados geofísicos de otros autores. La cartografía en estos sectores no evidenció litología volcánica, la geomorfología y algunas relaciones con la geofísica adquirida en el área, permiten suponer que se tratan de intrusiones sin expresiones superficiales aumentando las posibilidades de aporte de calor al sistema geotérmico.
\end{abstract}

Palabras clave: Domos riolíticos; Volcanismo Paipa; Sistema geotérmico de Paipa.

\section{New evidences of magmatism in the Paipa geothermal system, Boyacá, Colombia}

\begin{abstract}
The domes of the geothermal area of Paipa were characterized in three sectors. The Alto Los Volcanes is formed by two zones where four elevations are evident that protrude from the surface, with strongly weathered outcrops but with evident volcanic textures demarcated by big potassium feldspar crystals in a white matrix. In Quebrada Honda there is a domic structure dominated by feldspar megacrystals while the Alto Los Godos is formed by five domes with porphyritic texture and feldspar crystals. Petrographically similar characteristics are present in the three sectors, with the presence of potassium feldspar (sanidine/anortoclase) + plagioclase (albite) + amphibole (hornblende) + biotite. Variable amounts of kaolinite are shown especially for some feldspar replacements and as veins. Chemically, the domes are classified as rhyolites/trachidacites, with a chemical signature of subcalcaline magmas of calcoalkaline series rich in potassium typical of volcanic arcs. The REE shows an enrichment of the LREE with averages of $(\mathrm{La} / \mathrm{Sm})_{\mathrm{N}}$ between 5.944 and 14.726 respect to the HREE with values of $(\mathrm{Gd} / \mathrm{Yb})_{\mathrm{N}}$ between 0.626 and 2.318 and with an important positive anomaly of $\mathrm{Eu}_{\mathrm{N}} /\left(\mathrm{Sm}_{\mathrm{N}}{ }^{*} \mathrm{Gd}_{\mathrm{N}}\right)^{1 / 2}$ between 1.321 and 3.84. Data $\mathrm{Ar}-\mathrm{Ar}$ in amphibole and feldspar, gave as a result for the sector of Alto Los Volcanes and Quebrada Honda ages of 1.76 and 1.8 Ma respectively, on the other hand, for the Alto Los Godos were recorded for three domes ages of 2.8, 2.7 and 2.6 Ma. Evidences of intrusive bodies that have not emerged were identified in the north and south of the work area based on the geomorphology and geophysical results of other authors. The cartography in these sectors did not show volcanic lithology, the geomorphology and some relationships with the geophysics acquired in the area, allow us to suppose that they are intrusions without superficial expressions increasing the possibilities of heat contribution to the geothermal system.
\end{abstract}

Keywords: Rhyolitic domes; Paipa’s Volcanism; Paipa’s geothermal system.

\footnotetext{
${ }^{1}$ Grupo de Geotermia, Servicio Geológico Colombiano, Bogotá, Colombia. (*) jbrueda@sgc.gov.co, jbrueda86@gmail.com
} 


\section{Introducción}

El sistema geotérmico de Paipa se localiza en el Departamento de Boyacá, al sur del Municipio de Paipa, cubriendo un área de aproximadamente $110 \mathrm{~km}^{2}$ (Figura 1). Geográficamente, este sistema se encuentra en la Cordillera Oriental limitada al sur por el anticlinal Tibasosa-Toledo, al norte por el río Chicamocha, al este por la elevación del Alto de Los Godos y el Pantano de Vargas, y al oeste por el Alto Los Volcanes (Figura 1). La zona de estudio se caracteriza por presentar altos topográficos al este (Alto Los Godos) y al oeste (Alto Los Volcanes), y un lago al norte (lago Sochagota) y parte del Pantano de Vargas (Figura 1).

Paipa y su sistema geotérmico, ha sido objeto de varios estudios geológicos donde se ha definido un vulcanismo atípico en este punto de la Cordillera Oriental, dado que el vulcanismo principal en el país se restringe al norte y sur de la Cordillera Central y al sur de la Occidental, así como sus posibles sistemas geotérmicos asociados (CHEC, 1983). Trabajos como los de ENUSA-IAN (1979) y OLADE, GEOTÉRMICA ITALIANA, ICEL y CONTECOL (1982), posicionan a la zona de Paipa como de interés exploratorio para el recurso geotérmico, lo que ha motivado estudios a mayor detalle. Evidencias del vulcanismo del Pleistoceno y las manifestaciones hidrotermales dentro del área de estudio motivaron trabajos específicos en geoquímica (Alfaro, 2001, 2002, 2005), geología (Velandia, 2003; Cepeda y Pardo, 2004) y geofísica (Beltrán, 2015), entre otros. Si bien la razón del vulcanismo en este punto de la cordillera es de alguna manera incierta, el estudio más detallado de los productos eruptivos muestra varias etapas de una actividad explosiva principalmente, con pequeños eventos de intrusiones de domos (Cepeda y Pardo, 2004) que se relacionan con el sistema geotérmico de Paipa (Alfaro et al., 2017).

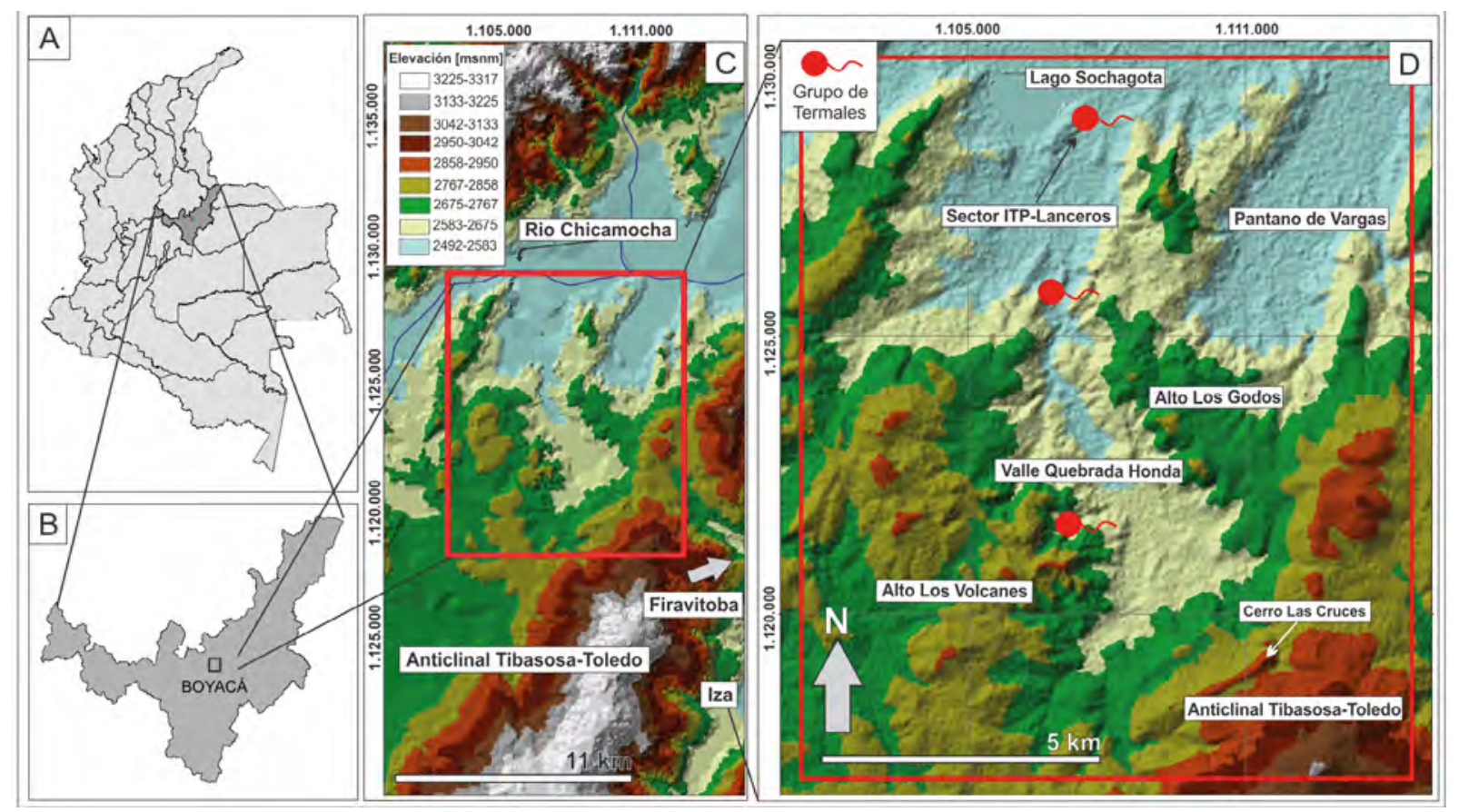

Figura 1. Localización del área del sistema geotérmico de Paipa. El recuadro rojo corresponde a la zona de estudio. A. Localización de Boyacá en el mapa de Colombia B. Localización del área de estudio en el Departamento de Boyacá. C. Área de estudio y sus alrededores. D. Área de estudio y manantiales termales.

En este trabajo se presenta la descripción de los productos efusivos (emplazamiento de cuerpos dómicos) que se observan en el área del sistema geotérmico de Paipa con base en trabajo de campo, pero también en análisis composicionales y geocronológicos propios, y en resultados de estudios geofísicos de estudios previos.

\section{Contexto geológico y antecedentes}

Los estudios más regionales y que hacen alusión al vulcanismo de Paipa como dos cuellos volcánicos, alterados y andesíticos, se presentan en la memoria explicativa del cuadrángulo J-12 de Renzoni y Rosas 
(1976) y el mapa en escala 1:100.000 (Renzoni y Rosas, 1967) para la plancha 171. Previo a estos trabajos, una de las primeras referencias que habla de actividad volcánica en el sector de Paipa se hace en Navia y Barriga (1929) donde se expresa que "las rocas eruptivas se han abierto paso en diversos puntos a través de los terrenos Cretáceos, dislocando las capas y diseminando por la superficie andesitas, porfirítas y piedra pómez". Sarmiento (1941) se refiere a las rocas volcánicas del Paipa como andesitas y pórfidos riolíticos y dacíticos. ENUSA-IAN (1979) menciona rocas volcánicas de textura porfirítica al este del área con presencia de fenocristales de feldespato intensamente caolinitizados y se refiere a rocas riodacítas porfiríticas que afloran al sur del área en la localidad de Olitas. Ferreira y Hernández (1988) hablan de tres lugares con exposición de cuerpos volcánicos. Uno de ellos es el sector de Olitas en donde se define el "Cuerpo Volcánico de Olitas" como un cuerpo cubierto por depósitos de aspecto sedimentario con fragmentos de rocas ígneas ácidas, metamórficas y sedimentarias en matriz arenosa y poco consolidada. El segundo cuerpo se encuentra en el extremo oriental del área, y es definido como "Cuerpo Volcánico de Pan de Azúcar", que corresponde a un cuerpo riolítico con textura porfirítica, el cual alberga cristales de cuarzo, plagioclasa y feldespato potásico. El tercer cuerpo se encuentra en el sector de La Llanada, definido como "Cuerpo Volcánico del Durazno" el cual corresponde a una brecha con fragmentos de limolitas, areniscas, carbones, embebidos en una matriz porosa. Hernández y Osorio (1990) analizan las rocas volcánicas del suroriente de Paipa donde reconocen dos domos de composición riolítica ubicados en el sector de Olitas y Vereda Venta de Llano, sector Pan de Azúcar. Este mismo trabajo muestra un total de 15 cortes geológicos en el sector del Alto Los Godos en dirección NE donde aún se ve más clara la extensión de las rocas efusivas. Los cuerpos volcánicos igualmente fueron descritos en Garzón (2003) agrupando en una sola unidad tanto los depósitos piroclásticos como las rocas volcánicas. El autor especifica que "la parte dómica puede ser observada claramente en la parte alta de la quebrada Calderón, al sur del Alto Peña de Santo, en el Alto los Godos, Agua Tibia y al sureste del sitio El Molino al costado derecho de la quebrada Honda".

Uno de los trabajos más completos, fue realizado por Velandia (2003) quien realiza el mapa geológico y estructural del área geotérmica de Paipa en escala 1:25.000. Este trabajo describe 10 unidades sedimentarias aflorantes en el área de estudio compuestas principalmente por niveles arenosos (areniscas cuarzosas), lodosos (shales y liditas) y algunas capas de calizas y mantos de carbón. Este autor también describe tres grupos importantes de fallas: un primer grupo lo componen las fallas transversales en dirección NE (El Hornito, Canocas y Santa Rita), un segundo grupo conformado por las fallas transversales en dirección NW (fallas Cerro Plateado y Paipa - Iza) y un tercer grupo formado por fallas longitudinales compuesto por las fallas El Bizcocho, Rancho Grande, Buena Vista, Agua Tibia y Lanceros, siendo estas dos últimas junto con Cerro Plateado y Paipa - Iza fallas que profundizan hasta el basamento de la zona. Además, este autor caracteriza el cuerpo intrusivo de El Durazno, como una brecha hidrotermal con intensa alteración hidrotermal (ver también González et al., 2008; Rodríguez y Alfaro, 2015).

Posteriormente, en Cepeda y Pardo (2004) se define el volcán de Paipa, con una descripción detallada de las unidades que lo conforman. Estos autores proponen dos periodos eruptivos compuestos por 14 unidades eruptivas. Un primer periodo que dio origen al edificio volcánico con erupciones explosivas sucesivas para finalmente producirse un colapso y dar origen a una caldera. El segundo periodo inicia con el emplazamiento de domos riolíticos y eventos de colapso de domos, así como caídas y oleadas piroclásticas de predominio freatomagmático. Estos autores describen la mineralogía de las rocas con presencia de anortoclasa, sanidina, oligoclasa y en menor proporción minerales máficos como biotita y hornblenda. Recientemente, Suárez (2016) propone el origen de los depósitos volcánicos del sector aquí llamado Alto Los Godos, como producto de erupciones explosivas provenientes de diferentes fuentes y descarta un colapso caldérico. Para el autor, estas fuentes serían las elevaciones del Alto Los Godos a las cuales les asocia lóbulos con extensiones restringidas y localizadas. El autor propone el vulcanismo de Paipa como un campo monogenético de composición acidaintermedia.

\section{Metodología}

Para el presente trabajo se realizaron 16 análisis petrográficos, 13 análisis de difracción de rayos $\mathrm{X}$ (DRX), 16 análisis químicos de elementos mayores y traza, 62 análisis de química mineral en dos muestras y 5 dataciones Ar-Ar.

Todos los análisis se realizaron en los laboratorios del Servicio Geológico Colombiano, con excepción de los 
análisis geocronológicos y microsonda electrónica. Los análisis de DRX fueron realizados en polvo desorientado con un equipo X-PERT PRO sin monocromador con fuente de rayos $\mathrm{X}$ de $\mathrm{Cu}$. Los análisis químicos de roca total fueron realizados a través de Fluorescencia de rayos X (FRX) para los elementos mayores y de un espectrómetro de masas inductivamente acoplado (ICP-MS por sus siglas en inglés) para los elementos traza. Los elementos mayores fueron analizados con un kit PANalytical AXIOS Minerals previa trituración de la muestra a un tamaño de $200 \mu \mathrm{m}$ usando una mandíbula y un molino de tungsteno, mientras que los elementos traza con un espectrómetro de masas con plasma de acoplamiento inductivo con célula de colisión KED, Mark PerkinElmer ${ }^{\circledR}$ referencia NexION 300D. El proceso previo consistió en: 1) pesar $10 \mathrm{~g}$ de muestra y añadir un aglutinante a la misma, la cual se homogeneizó y llevó a un aparato de prensado para formar una tableta para el caso de FRX y 2) separar 0,1 g de la muestra de digestión con ácido clorhídrico, nítrico y perclórico, obteniéndose un volumen de $10 \mathrm{ml}$ con la solución de ácido nítrico al 3\% v/v para el caso de ICP-MS. Los análisis de microsonda se realizaron en el Departamento de Geociencias de la Universidad Nacional de Colombia con un equipo JEOL superprobe JXA-8230 con tres canales de espectrómetros WDS. Finalmente, los análisis geocronológicos, se llevaron a cabo en los laboratorios de la Universidad Estatal de Oregón, Estados Unidos. La técnica se realizó con un espectrómetro de masas ARGUS-VI usando el método de calentamiento gradual. Para el caso en el que las muestras tenían una edad mínima tentativa de 2 Ma, se realizó una irradiación de 0,5 horas, cuando la edad fue mayor se irradió durante seis horas en el reactor TRIGA CLICIT. Las dataciones se realizaron en cristales de feldespato potásico, plagioclasa y anfíbol y los resultados se proporcionaron como la edad de la meseta (Plateau), los cuales se interpretaron como la edad de la erupción.

\section{Resultados}

La cartografía permitió definir un complejo de domos el cual será descrito a continuación separado por el rasgo más evidente que es la ubicación geográfica (Figura 2). Aunque estos domos son mapeados como estructuras aisladas, no se descarta que se presenten como cuerpos unidos por una raíz en profundidad, pero cerca de la superficie y teniendo algunas consideraciones estructurales estos se expresan como cuerpos separados.

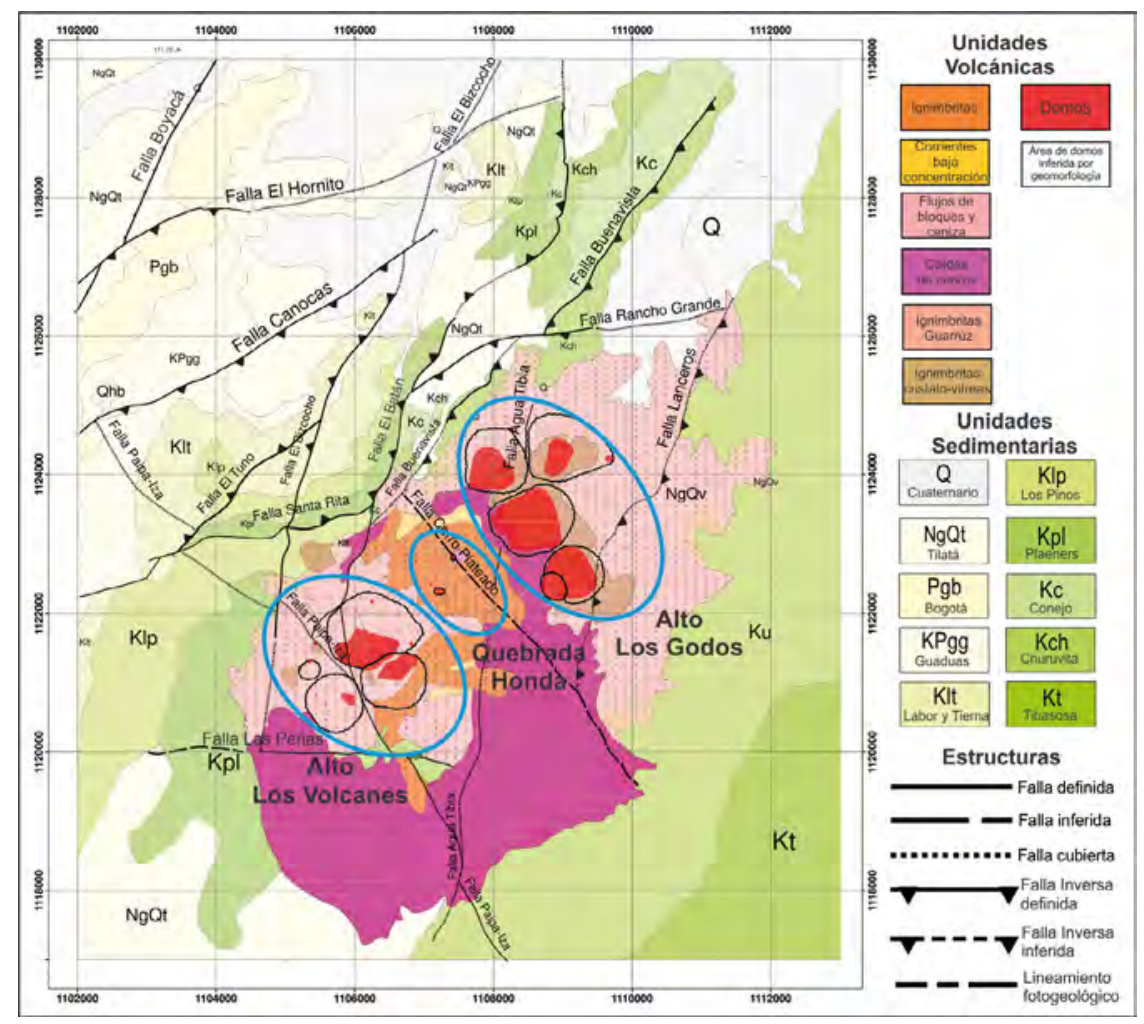

Figura 2. Mapa geológico del área geotérmica de Paipa que cubre el cuadrado rojo de la Figura 1. Editado de Velandia (2003), Cepeda y Pardo (2004) y Rueda-Gutiérrez (2017). 


\section{Evidencias de campo}

\section{Sector Alto Los Volcanes:}

Este sector se localiza al oeste del área de estudio (Figura 2) y está cubierto por flujos de bloques y ceniza con la presencia de fragmentos metamórficos y sedimentarios además de los volcánicos con textura porfirítica; este sector es propuesto por Cepeda y Pardo (2004) como el centro eruptivo Olitas. Al menos cuatro estructuras con geoformas dómicas evidentes se hallan en este punto cubiertas por depósitos piroclásticos. Si bien estas estructuras comparten un área específica, solo son separadas por depósitos y ligeras depresiones que las hacen ver como cuerpos diferentes, pero evidentemente se trata de toda un área levantada (zona de mayor elevación del área geotérmica de Paipa) con una altura máxima de $2849 \mathrm{~m}$ en el punto más alto (Figura 3A, 3B).

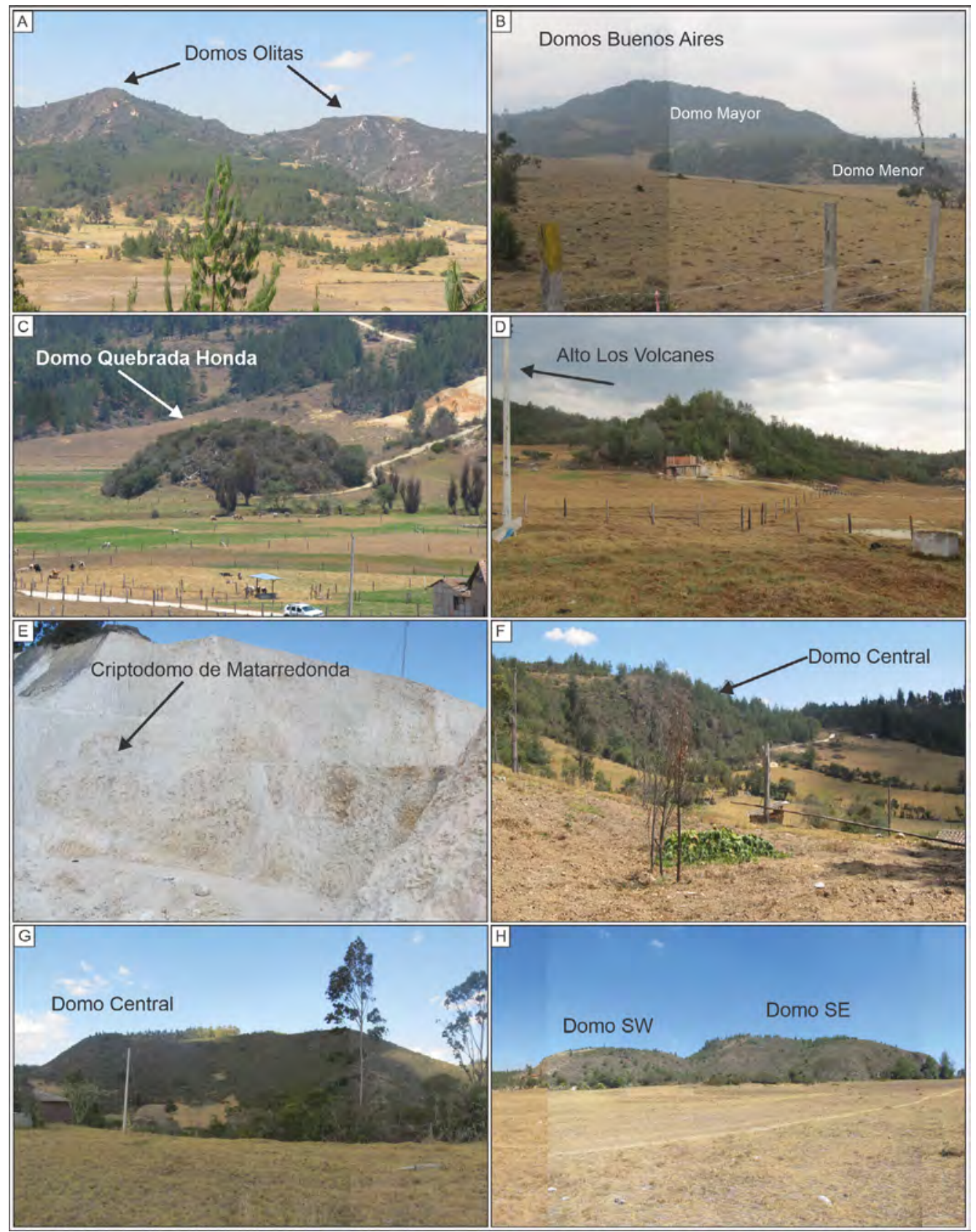

Figura 3. Fotografías panorámicas de los domos descritos en el presente estudio. A y B. Sector Alto Los Volcanes. C y D. Sector Quebrada Honda. E - H. Sector Alto Los Godos. 
Domos Orientales(Olitas): es el área de mayor extensión (aproximadamente $1,677 \mathrm{~km}^{2}$ uniendo los cuerpos a lado y lado de la quebrada Olitas), con una geoforma de domo no tan evidente debido a que la mayor parte del área está manteada por depósitos piroclásticos haciendo que la erosión del terreno sea más disectada de la que ocurriría en roca dura. Además, aunque el control litológico se da en numerosos afloramientos, este no es continuo especialmente al norte del área de estudio, pero el mapeo permitió unir estaciones de campo a lado y lado de la quebrada Olitas suponiendo dos estructuras separadas por esta quebrada. La Figura
3A muestra la forma de estas dos montañas donde es clara su morfología elevada respecto al valle de la quebrada Honda al NE. Como lo muestra la Figura 2, el área mapeada con evidencia de roca volcánica con textura porfirítica in situ se limita al borde de los cuerpos junto a los lados de la quebrada Olitas, lo cual se entiende por la alta elevación que favorece la erosión de los depósitos que cubren los domos. La roca luce muy meteorizada pero buenos afloramiento exponen roca volcánica porfirítica con fenocristales de feldespato dentro de una masa fundamental gris (Figura 4A).

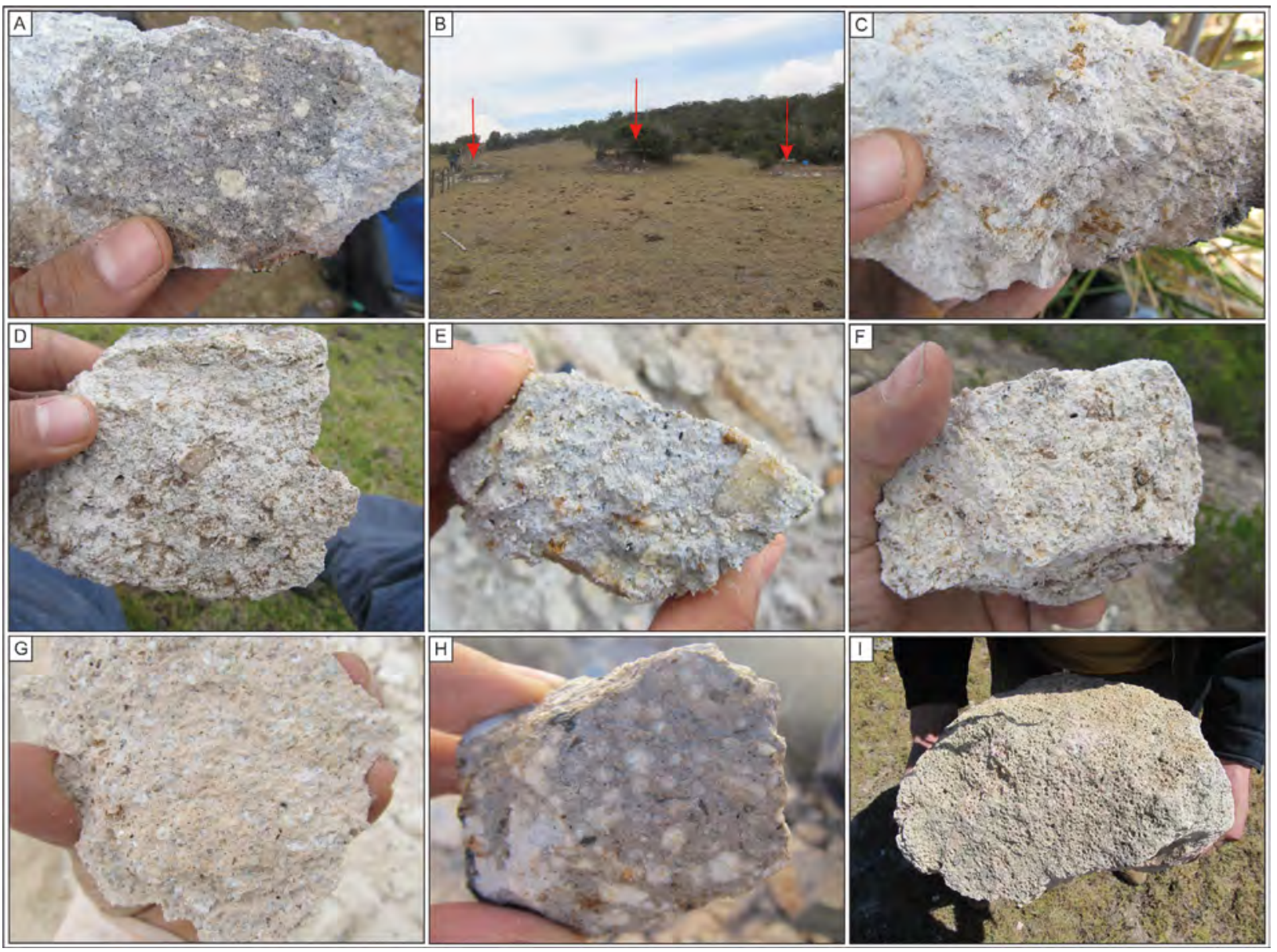

Figura 4. Fotografías de muestras de mano de los domos. A. Muestra de mano del domo Olitas B. Pequeños montículos porfiríticos sobre el domo occidental (flechas rojas). C. Muestra meteorizada del domo Olitas. D. y E. Muestras de mano del sector Quebrada Honda. F. y H. Muestras del sector Alto Los Godos. I. Muestra del domo NW. 
Domos Occidentales (Buenos Aires): se muestran como dos elevaciones (Figura 3B), con vegetación alta en medio de un área relativamente plana desprovista de árboles y solo con vegetación baja. Aunque se muestran como dos estructuras separadas, muy probablemente hagan parte de un solo cuerpo cuya cumbre cubierta por depósitos volcánicos haya sido erodada, dejando ver estos cuerpos volcánicos con textura porfirítica. La estructura mayor tiene forma casi perfectamente circular con evidentes pendientes y estructura dómica viéndose desde el NE al SW con una altura máxima de $2787 \mathrm{msnm}$ y de $2747 \mathrm{msnm}$ en su parte más baja y un área de $0,531 \mathrm{~km}^{2}$. En un sector en la cima de esta montaña se exponen pequeños afloramientos con pequeñas formas dómicas con una altura no mayor a los $2 \mathrm{~m}$ desde la base. Al menos son evidentes cuatro pequeñas elevaciones (Figura 4B) con un área menor a los $7 \mathrm{~m}^{2}$. En muestra de mano, estas rocas lucen igual a los cuerpos anteriormente descritos.

Varios afloramientos de roca in situ corroboran la litología en la base de la estructura, aunque esta luce muy meteorizada (Figura 4C), haciendo lucir a la roca como un depósito volcánico dado su bajo peso y la desaparición de algunos cristales o el cambio de color de estos. Es común ver cavidades dejadas por lo cristales, luciendo así como depósito piroclástico, pero es claro que se trata de huecos dejados por cristales ya removidos de la roca y no de porosidad (Figura 4C).

La estructura menor presenta un área aproximada de $0,067 \mathrm{~km}^{2}$ con una altura máxima de $2762 \mathrm{msnm}$ y de $2735 \mathrm{msnm}$ en su parte más baja (Figura 3B). Aunque son pocos los afloramientos, en la base la roca aflora al menos en tres lugares diferentes luciendo grandes cristales incoloros de feldespato y otros mucho más finos máficos.

\section{Sector Quebrada Honda:}

En el lugar topográficamente más bajo de toda la zona se expone un pequeño cuerpo de forma cóncava que sobresale del valle de la Quebrada Honda (Figura 3C). La estructura no sobrepasa un área de $4293 \mathrm{~m}^{2}$, con una altura de $2558 \mathrm{msnm}$ aproximadamente, sobresaliendo $8 \mathrm{~m}$ de la parte más baja que lo rodea. Esta estructura se encuentra cubierta por arbustos, aunque buenos afloramientos se pueden ver en el costado SW. Fracturas continuas son expuestas dejando caer grandes bloques angulosos a la base del afloramiento. En muestra de la mano la roca luce alterada en su masa fundamental, dándole un color blanco y muy endurecido. Resaltan grandes fenocristales de feldespatos cúbicos y rectangulares hasta de $2 \mathrm{~cm}$, aunque abundan los menores de 0,5 mm (Figura 4D); cristales máficos y algunos óxidos son visibles, pero en menor proporción y tamaño. En la roca se presentan, al igual que en los afloramientos del Alto Los Volcanes, cavidades en la roca dejadas por cristales removilizados.

Al costado SW del domo de Quebrada Honda, se encuentra aflorando una roca volcánica porfirítica de las mismas características al cuerpo antes descrito, con megacristales de feldespato. Aunque el afloramiento luce mayormente meteorizado haciendo que la masa fundamental y los cristales se puedan confundir, hay partes donde la roca es dura y la masa fundamental luce un color gris diferenciándose perfectamente de los fenocristales (Figura 4E). Visto desde el SE (Figura 3D) luce una geoforma de domo, pero por encima y visto desde el SW, no queda muy claro que se trate de un cuerpo aislado o de un megabloque desprendido desde los cuerpos dómicos del Alto Los Volcanes, ya que por detrás está siendo cubierto por depósitos volcánicos, mostrando una forma alargada que se extiende hasta la parte más alta de dicho alto.

\section{Sector Alto Los Godos:}

Esta área comprende el sector de La Mesa, Matarredonda y Alto Los Godos (Figura 2). Descrita en trabajos anteriores como depósitos ignimbríticos, pero con antecedentes que señalaban el carácter de roca volcánica coherente con textura porfirítica, resaltan cinco grandes elevaciones (estructuras dómicas) entre 2570 y $2770 \mathrm{msnm}$, las tres de ellas más evidentes por su altura están en dirección NW-SE (domo NW, domo central y domo SE) separados por depresiones suavizadas por depósitos volcánicos. Una cuarta elevación con 2696 msnm se ubica al SW de la estructura más al S (Figura 3E - 3G).

Criptodomo Matarredonda: se hace referencia aquí como criptodomo a un cuerpo de roca volcánica con textura porfirítica expuesta en las excavaciones realizadas por empresas mineras en el sector de Matarredonda. Topográficamente, visto desde el NW y $\mathrm{N}$, se logra ver una geoforma dómica con un área aproximada de $0,905 \mathrm{~km}^{2}$. Aunque se observan cantos rodados de rocas volcánicas en varios sectores en la cima de lo que sería la estructura dómica, evidentemente la litología que predomina son depósitos volcaniclásticos finos con líticos sedimentarios. Visitas a dos minas en la base de esta elevación, igualmente muestran depósitos volcanoclásticos con líticos sedimentarios, y una matriz blanca de ceniza con algunos sectores que 
lucen brechosos. Al costado E-NE, existen depósitos piroclásticos, mientras que hacia el $\mathrm{E}$ se observa roca coherente con textura porfirítica, mostrando una particular geoforma cóncava. La roca se muestra muy dura con un fracturamiento importante. En muestra de mano, la roca luce con masa fundamental rosada o blanca cuando está totalmente alterada; también son visibles cristales incoloros con los núcleos alterados de plagioclasa acompañados de cristales máficos más pequeños (Figura $4 \mathrm{G}$ ).

Domo NW: se expone como una estructura dómica con su cima alargada y aplanada con un área de $0,708 \mathrm{~km}^{2}$. La roca luce totalmente alterada de color blanco con tonos rojizos dado por la oxidación. En algunos casos los cristales han sido casi removidos por completo y la masa fundamental se ha meteorizado tanto que el peso específico de la roca es muy bajo pudiendo confundirse con un depósito piroclástico. La Figura 4I muestra un bloque de aproximadamente $50 \mathrm{~cm}$ cuyo peso no superaba $1,5 \mathrm{~kg}$, aun así, rastros de cristales de hasta 1 $\mathrm{cm}$ incoloros y algunos más finos máficos son visibles si se rompe la roca más profundo.

Domo Central: es la estructura más grande en cuanto a volumen se refiere con un área de $0,916 \mathrm{~km}^{2}$. Esta estructura se observa con una morfología muy resaltante con pendientes pronunciadas vistas desde el W. Desde la cima del domo NW se ve claramente la geoforma que delata este cuerpo con una pendiente pronunciada al SW (Figura 3F, 3G). La roca luce similar a la descrita con anterioridad (Figura 4H).

Domos SE y SW: al S del complejo de domos, dos estructuras dómicas sobresalen de la topografía relativamente llana del valle de la quebrada Honda con un área total de $0,586 \mathrm{~km}^{2}$. Vistos desde el Alto Los Volcanes (Figura $3 \mathrm{H}$ ) se logra ver estas dos estructuras, una más grande y alta que la otra, cubiertas por vegetación compuesta por pinos y arbustos, haciendo que resalten del paisaje de potrero y pasto corto y quemado de la zona baja y plana. El control litológico se observa claramente en varios lugares y en especial en una cantera en el domo SE donde se expone la roca fresca.

\section{Petrografía y Difracción de Rayos X (DRX)}

La mineralogía de todos los cuerpos está dominada por microfenocristales y fenocristales de plagioclasa (Figura 5A) y feldespato potásico (Figura 5B y 5D), con ligeras variaciones en las cantidades. En menor proporción se hallan microfenocristales de minerales máficos como biotita y hornblenda (Figura $5 \mathrm{C}, 5 \mathrm{~F}, 5 \mathrm{G}$ y $5 \mathrm{H}$ ) siendo estos dos cristales los que se muestran más alterados a óxidos. La masa fundamental es mayormente microcristalina a criptocristalina con variables cantidades de vidrio. Los cristales de feldespato muestran sus formas bien definidas, pero en el caso de los cristales máficos (hornblenda y biotita) se observan bordes corroídos o bahías de disolución.

La mayoría de microcristales de feldespato presentan un núcleo compuesto por un material isotrópico (Figura $6 \mathrm{~A}$ - 6D). Este material es reportado en otros trabajos (Pardo, 2004; Monsalve et al., 2011) y fue descrito por Martínez (1989) como vidrio que reemplaza los núcleos de los cristales en un cuerpo dómico al SE de Paipa. Esta característica se muestra comúnmente en las muestras de los tres sectores de domos. Este material isotrópico (vidrio volcánico), claramente se ve en algunas muestras como que invade los cristales desde sus bordes hasta el núcleo por medio de fracturas (Figura 6E, 6F). En las rocas, también son comunes los núcleos de plagioclasa dentro de los cristales de feldespato potásico posteriormente reemplazados por el vidrio que a su vez es modificado a caolinita.

Los análisis de DRX confirman lo observado bajo el microscopio petrográfico, con algunas particularidades. La fase cristalina que predomina en todas las muestras es la anortoclasa y albita seguidas de la sanidina (Tabla 1). Los porcentajes de biotita y hornblenda no se representan en el porcentaje que son vistos bajo el microscopio. El vidrio tampoco fue cuantificado aunque es indicado por algunas inflexiones en los difractogramas de algunas muestras (Figura 7D). Los análisis también revelan un porcentaje muy alto en el contenido de caolinita en algunas de las muestras. El porcentaje más importante pertenece a un relleno de vetillas localizadas en el domo SW del sector Alto Los Godos evidenciando una alteración argílica. Este relleno se dispone en un enrejado que corta la roca la cual está casi inalterada (Figura 7A y 7B). Los otros porcentajes de caolinita son también reflejados en varias muestras de bloques rodados muy meteorizados, por lo que en este caso, no se descarta que se trata de una alteración superficial que ha alterado los contenidos de vidrio fácilmente modificables a la intemperie. 

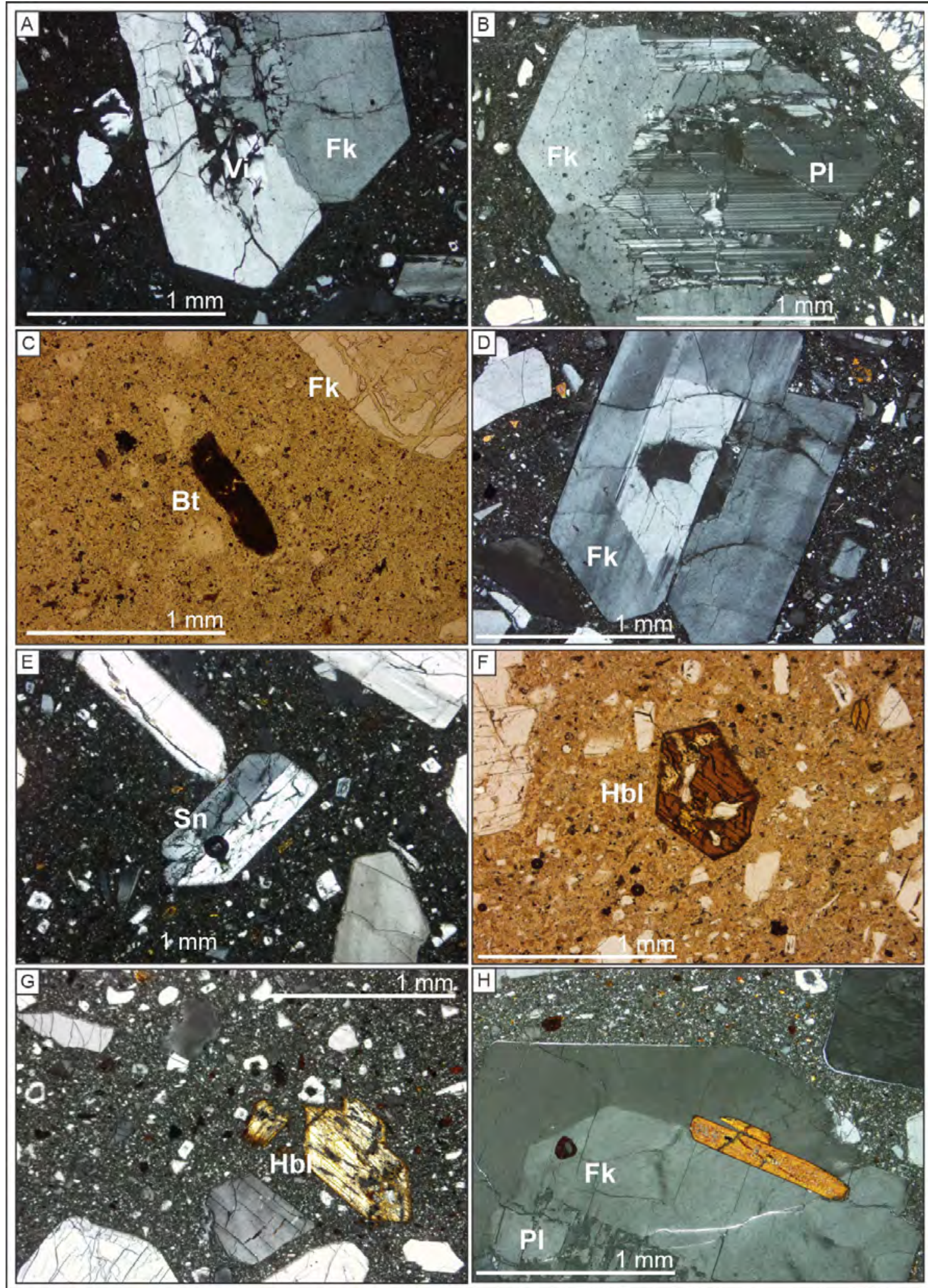

Figura 5. Fotomicrografías de algunas texturas del complejo de domos. A. Cristal de feldespato potásico con núcleo reemplazado. B. Fenocristales de feldespatos con núcleo de plagioclasa. C. Microcristal de biotita. D. Fenocristales de feldespato. E. Microcristal de sanidina en matriz vítrea F. Microcristal de anfíbol. G. Anfíbol alterado. H. Megacristales de feldespato con inclusión de anfíbol. 


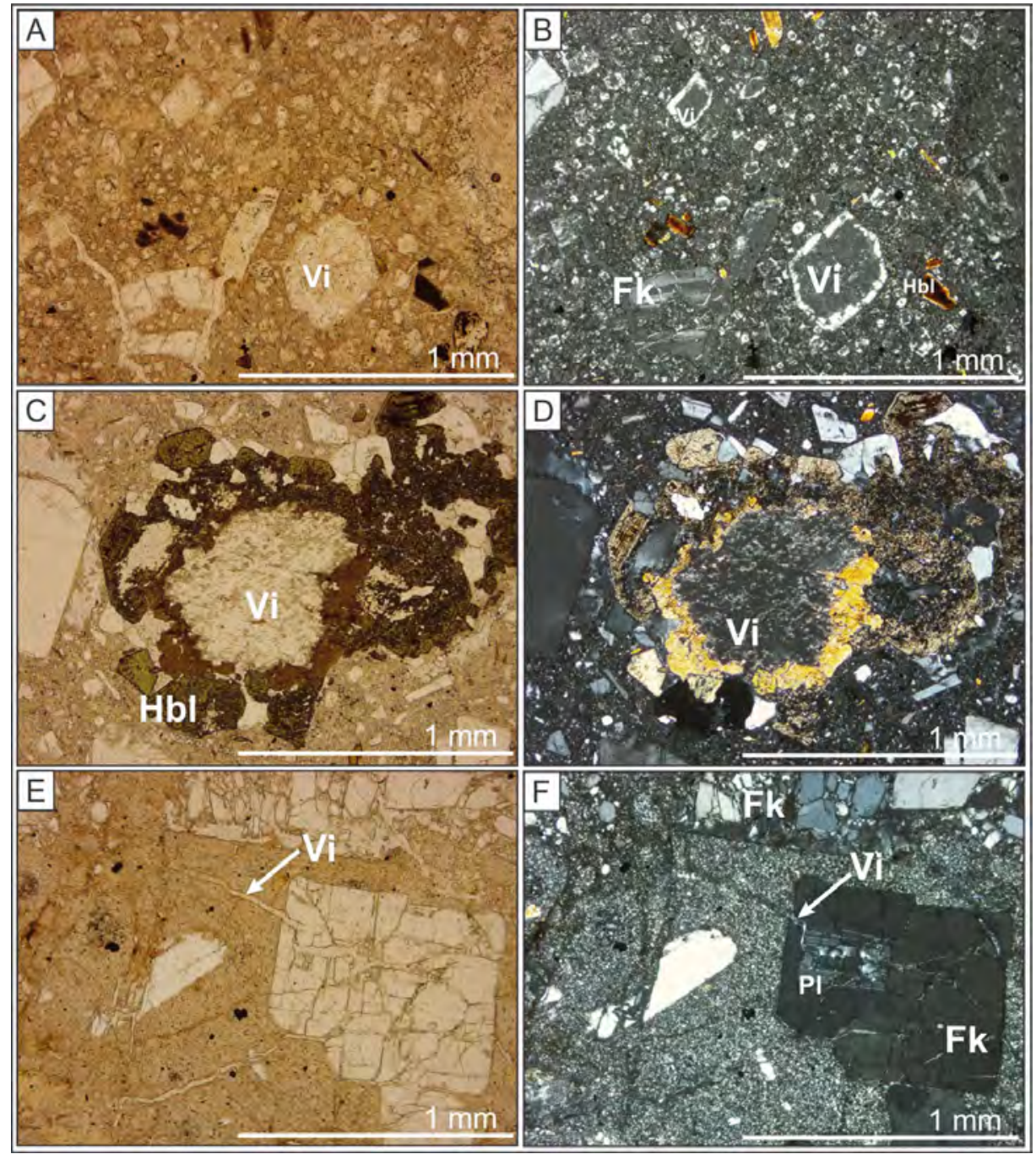

Figura 6. Fotomicrografías que muestran el reemplazamiento de los núcleos de los cristales por vidrio volcánico (Vi). A. y B. Núcleos de feldespato reemplazados por vidrio. C. y D. Cristal de anfíbol con núcleo reemplazado. E. y F. Vidrio entrando a microfenocristales de plagioclasa, dentro de fenocristal de feldespato potásico.

Tabla 1. Resultados del análisis de DRX para las muestras de los tres complejos de domos.

\begin{tabular}{|c|c|c|c|c|c|c|c|c|c|c|c|c|c|}
\hline \multirow[b]{2}{*}{ Muestra } & \multicolumn{7}{|c|}{ Alto Los Volcanes } & \multicolumn{2}{|c|}{ Quebrada Honda } & \multicolumn{4}{|c|}{ Alto Los Godos } \\
\hline & JR-092 & JR-123 & JR-126 & JR-134 & GR-023 & GR-033-1 & GR-067 & JR-045 & JR-129 & JR-047 & JR-082 & JR-116 & JR-117 \\
\hline Albita & 46,3 & -- & 26,4 & 34,4 & 44,5 & 41,1 & 6,7 & 26,6 & 37,4 & 58 & 32,4 & 42 & 12 \\
\hline Anortita & 30,2 & 6,7 & 28,1 & 20,6 & 22,7 & 21,1 & 53 & 64,3 & 54,9 & -- & 42,8 & 23.4 & 77 \\
\hline Sanidina & 11,8 & -- & 22,8 & 20,4 & 18,3 & 21,1 & 26,1 & -- & -- & -- & 17,7 & 19.8 & -- \\
\hline Ortoclasa & -- & 23,9 & -- & -- & -- & -- & -- & -- & -- & 23 & -- & -- & -- \\
\hline Cuarzo & 3,1 & -- & 5,7 & 24,6 & 1,9 & 16,1 & $<1,0$ & -- & 1,8 & 18,8 & 3,7 & 14.9 & 11 \\
\hline Biotita & -- & 1,5 & -- & -- & -- & -- & -- & -- & -- & -- & -- & -- & $<0,1$ \\
\hline Hornblenda & -- & -- & -- & -- & -- & -- & $<1,0$ & -- & $<1,0$ & -- & -- & -- & -- \\
\hline Mica & -- & -- & 2,2 & -- & -- & $<1,0$ & -- & -- & -- & -- & -- & -- & -- \\
\hline Cristobalita & 3,1 & -- & 8 & -- & -- & -- & 13,3 & 7,9 & 5,9 & -- & 3,4 & -- & -- \\
\hline Hedenbergita & -- & -- & -- & -- & -- & -- & -- & $<2,0$ & -- & -- & -- & -- & -- \\
\hline Caolinita & -- & 67,9 & 6,8 & $<1,0$ & 9,9 & $<1,0$ & -- & -- & -- & -- & -- & -- & \\
\hline
\end{tabular}



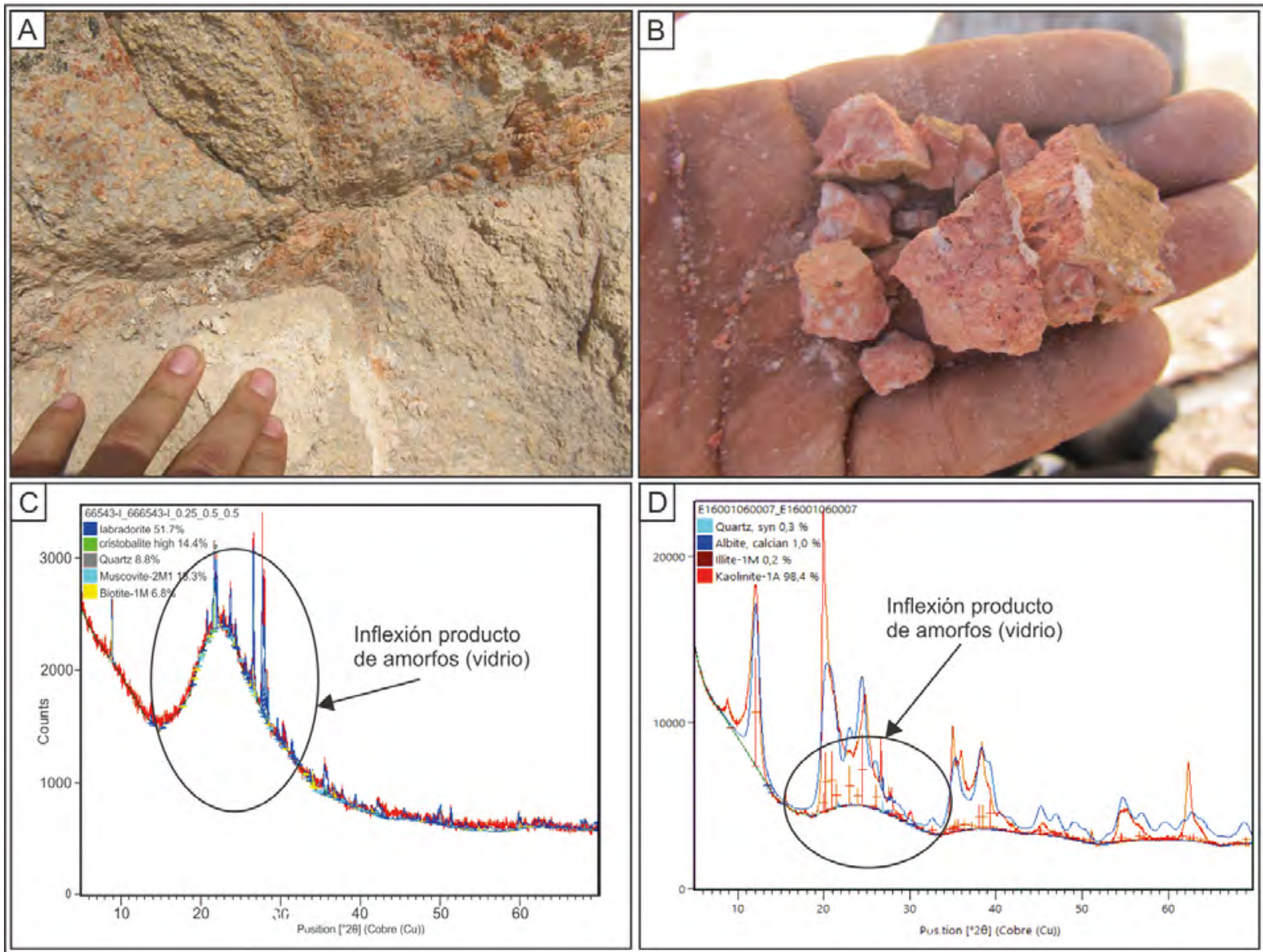

Figura 7. Domo SE con abundante caolinita. A. B. Fotografías que muestran la disposición de la caolinita en el domo. C. Ejemplo representativo de un resultado de DRX de muestra con alto contenido de vidrio y por lo tanto una inflexión en el difractograma. D. Difractograma de la muestra tomada del domo SE.

\section{Geoquímica}

Un total de siete muestras del sector Alto Los Volcanes, dos de Quebrada Honda y siete del Alto Los Godos fueron analizadas (Tabla 2). La característica predominante de la zona es la alta meteorización que presentan la mayoría de afloramientos, solo es expuesta roca endurecida y con los fenocristales más conservados en los sectores donde se han abierto canteras recientes, esto en el criptodomo de Matarredonda como en el domo SE del Alto Los Godos. En general las muestras de los tres sectores presentan composiciones muy similares con promedios de $\mathrm{SiO}_{2}$ de 69,87 wt. $\%$, $\mathrm{TiO}_{2}$ de 0,21 wt. $\%, \mathrm{Fe}_{2} \mathrm{O}_{3} \mathrm{~T}$ de 1,69 wt. $\%$ y $\mathrm{Al}_{2} \mathrm{O}_{3}$ de 17,90 wt. $\%$ con promedios más bajos para el sector de Quebrada Honda. El MgO muestra valores similares en el Alto Los Volcanes y Quebrada Honda, y ligeramente más bajos para el Alto
Los Godos, con la mayoría de los datos por debajo del límite de detección. El CaO muestra un promedio de 0,38 wt. $\%$, pero se evidencia un porcentaje más bajo para el Alto Los Godos respecto a Quebrada Honda y Alto Los Volcanes. El $\mathrm{Na}_{2} \mathrm{O}$ se promedia en 5,93 wt.\%, el $\mathrm{K}_{2} \mathrm{O}$ en 3,87 wt. $\%$, y el $\mathrm{P}_{2} \mathrm{O}_{5}$ en 0,028 wt. $\%$.

De acuerdo con lo anterior, las rocas se clasifican como riolitas y traquitas según el diagrama TAS (Figura 8A), y se confirman el carácter traquítico con el diagrama de Winchester y Floyd (1977) (Figura 8B). Todas las muestras caen en el campo de la serie calcoalcalina rica en potasio (Figura 8C y 8D) con firmas químicas de magmatismo de arco volcánico (Figura 8E y 8F) según los diagramas de Pearce et al. (1984). Según los contenidos de $\mathrm{La}, \mathrm{Yb}$ se observa una firma adakítica para todas las muestras analizadas (Figura 8G y 8H). 
Tabla 2. Resultados de elementos mayores (recalculados), menores y traza.

\begin{tabular}{|c|c|c|c|c|c|c|c|c|c|c|c|c|c|c|c|c|}
\hline \multirow[b]{2}{*}{ Muestra } & \multicolumn{7}{|c|}{ Alto Los Volcanes } & \multicolumn{2}{|c|}{ Quebrada Honda } & \multicolumn{7}{|c|}{ Alto Los Godos } \\
\hline & JR-092-1 & JR-124-1 & JR-126-1 & JR-134-1 & GR-023-1 & GR-033-1 & GR-067-1 & JR-045-1 & JR-129-11 & JR-047-1 & JR-048-1 & JR-082-1 & JR-090-1 & JR-097-1 & JR-0116-1-A & JR-117-1 \\
\hline Longitud & $-73^{\circ} 7,492^{\prime}$ & $-73^{\circ} 7,470^{\prime}$ & $-73^{\circ} 7,260^{\prime}$ & $-73^{\circ} 7,108^{\prime}$ & $-73^{\circ} 7,033^{\prime}$ & $-73^{\circ} 7,065^{\prime}$ & $-73^{\circ} 7,386^{\prime}$ & $-73^{\circ} 6,475^{\prime}$ & $-73^{\circ} 6,547^{\prime}$ & $-73^{\circ} 5,697^{\prime}$ & $-73^{\circ} 6,215^{\prime}$ & $-73^{\circ} 5,716^{\prime}$ & $-73^{\circ} 5,841^{\prime}$ & $-73^{\circ} 6,072^{\prime}$ & $-73^{\circ} 5,410^{\prime}$ & $-73^{\circ} 5,234^{\prime}$ \\
\hline Latitud & $5^{\circ} 41,555$ & $5^{\circ} 41,212^{\prime}$ & $5^{\circ} 41,262^{\prime}$ & $5^{\circ} 42,024^{\prime}$ & $5^{\circ} 41,420^{\prime}$ & $5^{\circ} 41,523$ & $5^{\circ} 41,917$ & $5^{\circ} 42,340^{\prime}$ & $5^{\circ} 42,091$ & $5^{\circ} 43,059^{\prime}$ & $5^{\circ} 42,935^{\prime}$ & $5^{\circ} 42,066^{\prime}$ & $5^{\circ} 42,560$ & $5^{\circ} 43,006$ & $5^{\circ} 42,178$ & $5^{\circ} 43,111^{\prime}$ \\
\hline Elemento & $\mathbf{W t} \%$ & $\mathrm{Wt} \%$ & $\mathbf{W t} \%$ & $\mathbf{W t} \%$ & $\mathbf{W t} \%$ & $\mathrm{Wt} \%$ & $\mathrm{Wt} \%$ & Wt $\%$ & $\mathbf{W t} \%$ & Wt $\%$ & Wt\% & $\mathbf{W t} \%$ & Wt\% & $\mathbf{W t} \%$ & Wt $\%$ & $\mathrm{Wt} \%$ \\
\hline $\mathrm{SiO}_{2}$ & 70,95 & 66,91 & 67,57 & 71,42 & 68,64 & 71,00 & 70,95 & 70,99 & 70,42 & 70,79 & 68,17 & 69,61 & 68,56 & 69,06 & 69,28 & 69,55 \\
\hline $\mathrm{TiO}_{2}$ & 0,16 & 0,33 & 0,32 & 0,15 & 0,30 & 0,18 & 0,17 & 0,12 & 0,19 & 0,24 & 0,28 & 0,23 & 0,27 & 0,25 & 0,28 & 0,24 \\
\hline $\mathrm{Al}_{2} \mathrm{O}_{3}$ & 17,65 & 19,76 & 20,51 & 17,89 & 18,73 & 18,24 & 17,40 & 16,91 & 16,76 & 17,34 & 20,31 & 17,61 & 18,81 & 17,96 & 18,56 & 17,12 \\
\hline $\mathrm{Fe}_{2} \mathrm{O}_{3}$ & 1,00 & 2,59 & 1,96 & 1.23 & 2,10 & 1,18 & 1,18 & 1,28 & 1,46 & 1,86 & 2,57 & 1,98 & 2,16 & 2,05 & 2,16 & 1,99 \\
\hline MgO & 0 & 0,55 & 0,39 & 0 & 0,40 & 0 & 0 & 0,1 & 0,17 & 0,1 & 0 & 0 & 0 & 0 & 0 & 0 \\
\hline MnO & 0,02 & 0,07 & 0,04 & 0,03 & 0,03 & 0,01 & 0.03 & 0,05 & 0,05 & 0,03 & 0,09 & 0,04 & 0,06 & 0,04 & 0,03 & 0,04 \\
\hline $\mathrm{CaO}$ & 0,19 & 0,55 & 0,46 & 0,13 & 0,61 & 0 & 0,21 & 0,38 & 0,53 & 0,11 & 0,14 & 0,18 & 0,18 & 0,20 & 0,13 & 0,18 \\
\hline $\mathrm{Na}_{2} \mathrm{O}$ & 5,87 & 5,34 & 4,98 & 4,93 & 5,41 & 5,24 & 6,17 & 6,42 & 6,61 & 5,56 & 5,14 & 6,11 & 5,84 & 6,22 & 5,53 & 6,65 \\
\hline $\mathbf{K}_{2} \mathbf{O}$ & 3,63 & 3,80 & 3,70 & 4,17 & 3,73 & 4,08 & 3,89 & 3,73 & 3,80 & 3,94 & 3,27 & 4,22 & 4,08 & 4,21 & 3,99 & 4,20 \\
\hline $\mathbf{P}_{2} \mathbf{O}_{5}$ & 0,02 & 0,09 & 0,07 & 0,03 & 0,07 & 0,06 & 0 & 0,02 & 0 & 0,03 & 0,05 & 0,03 & 0,03 & 0 & 0,03 & 0,03 \\
\hline LOI & 1,6 & 4,22 & 3,3 & 2,24 & 2,45 & 2,47 & 1,33 & 0,65 & 0,52 & 1,48 & 3,5 & 1,44 & 2,07 & 1,38 & 2,1 & 0,61 \\
\hline $\mathrm{FeO}^{*}$ & 0,13 & 0,36 & 0,13 & 0,13 & 0,13 & 0,13 & 0,13 & 0,19 & 0,13 & 0,13 & 0,13 & 0,13 & 0,14 & 0,18 & 0,21 & 0,14 \\
\hline Elemento & ppm & ppm & ppm & ppm & ppm & ppm & ppm & ppm & ppm & ppm & ppm & ppm & ppm & ppm & ppm & ppm \\
\hline $\mathrm{Zr}$ & 175 & 232 & 218 & 168 & 207 & 177 & 167 & 163,7 & 160 & 218,8 & 234 & 210 & 219 & 210 & 229 & 196 \\
\hline $\mathbf{N b}$ & 22 & 22 & 22 & 22 & 20 & 23 & 22 & 18,7 & 18 & 31,6 & 33 & 30 & 32 & 30 & 34 & 29 \\
\hline $\mathbf{v}$ & 14 & 35 & 40 & 17 & 39 & 23 & 19 & 10 & 20 & 20 & 34 & 28 & 35 & 31 & 14 & 37 \\
\hline $\mathbf{L i}$ & 32,387 & 25,656 & 32,435 & 46,820 & 35,794 & 19,742 & 26,607 & 49,73 & 34,38 & 51,61 & 35,610 & 34,548 & 40,661 & 40,712 & 40,174 & 35,956 \\
\hline Be & 3,251 & 3,972 & 3,710 & 5,588 & 3,734 & 4,176 & 4,0505 & 7,89 & 3,826 & 7,34 & 2,478 & 2,613 & 2,840 & 3,008 & 4,376 & 3,787 \\
\hline Sc & 3,458 & 6,306 & 5,009 & 1,546 & 3,745 & 2,358 & 1,907 & 2,86 & 3,392 & 5,13 & 3,452 & 2,858 & 4,004 & 4,132 & 3,695 & 3,243 \\
\hline $\mathbf{N i}$ & 1,079 & 3,614 & 2,992 & 0,873 & 3,741 & 1,099 & 1,307 & 2,05 & 1,25 & 6,34 & 1,531 & 1,105 & 2,682 & 1,639 & 1,266 & 2,088 \\
\hline $\mathrm{Cu}$ & 3,356 & 6,212 & 4,795 & 3,237 & 4,211 & 3,161 & 3,747 & 5,66 & 3,75 & 5,64 & 7,608 & 5,182 & 5,474 & 6,06 & 4,555 & 5,087 \\
\hline Zn & 28,879 & 74,401 & 68,951 & 35,845 & 53,593 & 61,594 & 37,496 & 77,26 & 56,333 & 67,10 & 77,938 & 68,151 & 72,55 & 63,82 & 58,39 & 54,422 \\
\hline Ga & 29,877 & 31,503 & 31,991 & 26,427 & 26,634 & 27,585 & 26,214 & 30,28 & 28,01 & 35,62 & 33,758 & 29,282 & 31,658 & 30,055 & 33,86 & 30,122 \\
\hline $\mathbf{R b}$ & 143,232 & 1,695 & 150,087 & 186,985 & 137,731 & 183,619 & 164,808 & 133,17 & 131,44 & 149,69 & 51,174 & 152,779 & 143,283 & 147,02 & 132,915 & 144,626 \\
\hline $\mathrm{Sr}$ & 749,007 & 509,595 & 716,377 & 545,452 & 749,369 & 651,919 & 671,177 & 1169,62 & 931,719 & 1413,62 & 1156,089 & 1080,506 & 1112,3 & 1131,195 & 1051,906 & 1169,897 \\
\hline $\mathbf{Y}$ & 5 & 8 & 14 & 8 & 8 & 7 & 4 & 10,5 & 7 & 10,7 & 7 & 4 & 4 & 2 & 15 & 4 \\
\hline Cd & 0,127 & 0,162 & 0,138 & 0,119 & 0,137 & 0,142 & 0,173 & 0,16 & 0,151 & 0,20 & 0,214 & 0,176 & 0,184 & 0,187 & 0,221 & 0,204 \\
\hline In & 0,017 & 0,024 & 0,026 & 0,017 & 0,023 & 0,02 & 0,017 & 0,02 & 0,018 & 0,03 & 0,022 & 0,019 & 0,022 & 0,019 & 0,022 & 0,02 \\
\hline Cs & 1,286 & 0,672 & 0,826 & 1,996 & 0,872 & 1,169 & 1,697 & 1,37 & 0,581 & 1,04 & 0,405 & 0,956 & 0,534 & 0,563 & 0,517 & 0,453 \\
\hline Ba & 1554,701 & 1248,275 & 1263,286 & 1619,347 & 1634,289 & 1604,531 & 1608,105 & 2549,48 & 1631,485 & 2771,71 & 2113,655 & 1749,941 & 2046,442 & 1805,986 & 1775,212 & 357,513 \\
\hline
\end{tabular}




\begin{tabular}{|c|c|c|c|c|c|c|c|c|c|c|c|c|c|c|c|c|}
\hline \multirow[b]{2}{*}{ Muestra } & \multicolumn{7}{|c|}{ Alto Los Volcanes } & \multicolumn{2}{|c|}{ Quebrada Honda } & \multicolumn{7}{|c|}{ Alto Los Godos } \\
\hline & JR-092-1 & JR-124-1 & JR-126-1 & JR-134-1 & GR-023-1 & GR-033-1 & GR-067-1 & JR-045-1 & JR-129-11 & JR-047-1 & JR-048-1 & JR-082-1 & JR-090-1 & JR-097-1 & JR-0116-1-A & JR-117-1 \\
\hline Longitud & $-73^{\circ} 7,492^{\prime}$ & $-73^{\circ} 7,470^{\prime}$ & $-73^{\circ} 7,260^{\prime}$ & $-73^{\circ} 7,108^{\prime}$ & $-73^{\circ} 7,033^{\prime}$ & $-73^{\circ} 7,065^{\prime}$ & $-73^{\circ} 7,386^{\prime}$ & $-73^{\circ} 6,475^{\prime}$ & $-73^{\circ} 6,547^{\prime}$ & $-73^{\circ} 5,697^{\prime}$ & $-73^{\circ} 6,215^{\prime}$ & $-73^{\circ} 5,716^{\prime}$ & $-73^{\circ} 5,841^{\prime}$ & $-73^{\circ} 6,072^{\prime}$ & $-73^{\circ} 5,410^{\prime}$ & $-73^{\circ} 5,234^{\prime}$ \\
\hline Latitud & $5^{\circ} 41,555^{\prime}$ & $5^{\circ} 41,212^{\prime}$ & $5^{\circ} 41,262^{\prime}$ & $5^{\circ} 42,024^{\prime}$ & $5^{\circ} 41,420^{\prime}$ & $5^{\circ} 41,523^{\prime}$ & $5^{\circ} 41,917$ & $5^{\circ} 42,340^{\prime}$ & $5^{\circ} 42,091^{\prime}$ & $5^{\circ} 43,059^{\prime}$ & $5^{\circ} 42,935$ & $5^{\circ} 42,066^{\prime}$ & $5^{\circ} 42,560^{\prime}$ & $5^{\circ} 43,006$ & $5^{\circ} 42,178^{\prime}$ & $5^{\circ} 43,111^{\prime}$ \\
\hline Elemento & ppm & ppm & ppm & ppm & ppm & ppm & ppm & ppm & ppm & ppm & ppm & ppm & ppm & ppm & ppm & ppm \\
\hline $\mathbf{L a}$ & 13,656 & 33,683 & 29,782 & 10,022 & 31,446 & 14,869 & 9,868 & 26,96 & 14,948 & 44,83 & 60,569 & 15,793 & 12,77 & 9,409 & 15,555 & 10,379 \\
\hline $\mathrm{Ce}$ & 15,926 & 61,181 & 51,097 & 66,254 & 61,424 & 31,541 & 17,84 & 30,05 & 23,42 & 31,04 & 39,506 & 40,684 & 36,881 & 39,885 & 24,899 & 46,057 \\
\hline $\operatorname{Pr}$ & 1,718 & 6,04 & 4,961 & 1,404 & 5,687 & 2,865 & 1,325 & 5,32 & 2,885 & 5,36 & 9,049 & 1,753 & 2,638 & 1,46 & 4,72 & 2,536 \\
\hline Nd & 5,022 & 13,356 & 11,807 & 2,769 & 14,462 & 6,18 & 4,402 & 16,16 & 10,024 & 14,74 & 22,93 & 1,045 & 5,489 & 0,96 & 18,411 & 4,631 \\
\hline Sm & 0,746 & 3,025 & 2,871 & 0,824 & 3,192 & 1,612 & 0,668 & 2,85 & 1,804 & 2,19 & 3,737 & 0,675 & 1,739 & 0,949 & 3,527 & 1,949 \\
\hline Eu & 0,719 & 1,217 & 1,136 & 0,822 & 1,329 & 0,982 & 0,794 & 1,25 & 1,087 & 1,24 & 1,6 & 0,847 & 1,153 & 0,907 & 1,502 & 1,111 \\
\hline Gd & 0,735 & 2,647 & 2,829 & 0,973 & 2,743 & 1,534 & 0,703 & 2,51 & 1,616 & 2,06 & 3,158 & 0,816 & 1,352 & 0,827 & 2,95 & 1,454 \\
\hline $\mathbf{T b}$ & 0,102 & 0,329 & 0,386 & 0,119 & 0,316 & 0,201 & 0,101 & 0,33 & 0,224 & 0,25 & 0,357 & 0,097 & 0,196 & 0,11 & 0,43 & 0,228 \\
\hline Dy & 0,618 & 1,504 & 2,049 & 0,637 & 1,399 & 1,034 & 0,55 & 1,76 & 1,155 & 1,42 & 1,459 & 0,529 & 1,026 & 0,607 & 2,269 & 1,144 \\
\hline Ho & 0,139 & 0,271 & 0,414 & 0,135 & 0,252 & 0,194 & 0,128 & 0,34 & 0,236 & 0,30 & 0,28 & 0,121 & 0,197 & 0,111 & 0,47 & 0,205 \\
\hline Er & 0,502 & 0,849 & 1,271 & 0,467 & 0,787 & 0,639 & 0,484 & 1,12 & 0,74 & 1,08 & 0,934 & 0,444 & 0,691 & 0,383 & 1,557 & 0,662 \\
\hline $\mathrm{Tm}$ & 0,095 & 0,126 & 0,187 & 0,078 & 0,108 & 0,102 & 0,09 & 0,17 & 0,118 & 0,18 & 0,139 & 0,083 & 0,125 & 0,073 & 0,251 & 0,116 \\
\hline $\mathbf{Y b}$ & 0,808 & 0,949 & 1,326 & 0,633 & 0,815 & 0,822 & 0,771 & 1,32 & 0,933 & 1,42 & 1,144 & 0,727 & 1,075 & 0,629 & 1,877 & 0,96 \\
\hline Lu & 0,145 & 0,153 & 0,204 & 0,109 & 0,134 & 0,149 & 0,15 & 0,22 & 0,163 & 0,24 & 0,192 & 0,129 & 0,177 & 0,105 & 0,307 & 0,153 \\
\hline Tl & 0,469 & 0,293 & 0,335 & 2,509 & 0,994 & 0,186 & 0,505 & 0,67 & 0,462 & 0,24 & 0,45 & 0,411 & 0,163 & 0,428 & 0,209 & 0,53 \\
\hline $\mathbf{P b}$ & 33,675 & 23,823 & 23,846 & 41,395 & 23,858 & 27,035 & 30,588 & 34,33 & 26,024 & 20,69 & 16,914 & 25,534 & 23,659 & 22,451 & 20,732 & 19,468 \\
\hline $\mathbf{B i}$ & 0,267 & 0,083 & 0,102 & 0,606 & 0,165 & 0,135 & 0,228 & 0,17 & 0,178 & 0,10 & 0,166 & 0,203 & 0,151 & 0,127 & 0,158 & 0,14 \\
\hline Th & 8,884 & 9,987 & 9,372 & 5,673 & 8,377 & 6,332 & 9,235 & 7,96 & 8,355 & 13,03 & 15,487 & 12,566 & 14,091 & 12,913 & 14,867 & 11,552 \\
\hline $\mathbf{U}$ & 5,624 & 3,752 & 4,088 & 4,14 & 3,996 & 3,152 & 6,099 & 4,82 & 4,344 & 6,94 & 6,711 & 6,877 & 5,547 & 6,12 & 6,806 & 5,52 \\
\hline
\end{tabular}

*FeO reportado por el laboratorio. 

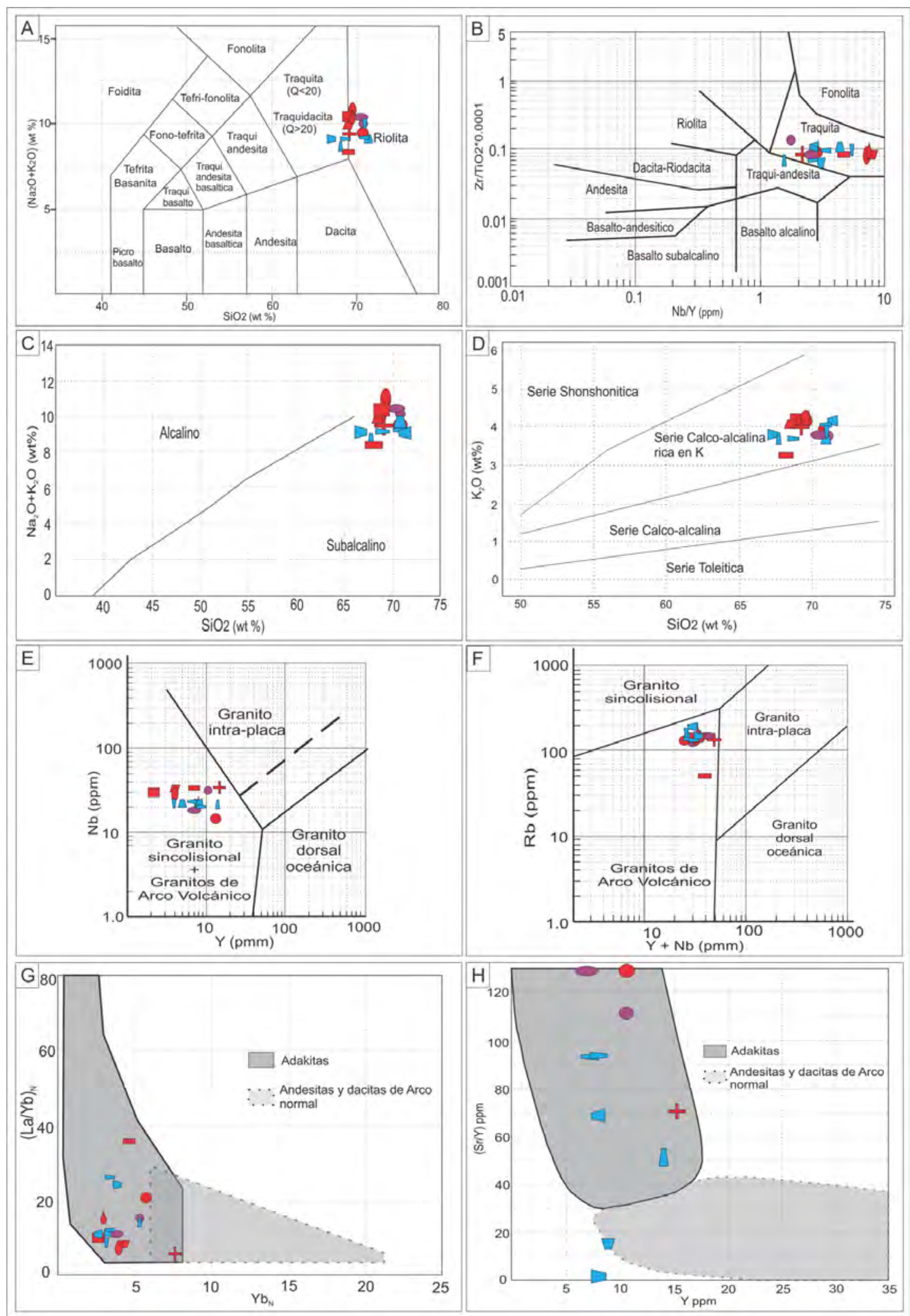

Figura 8. Diagramas de clasificaciones químicas para los cuerpos porfiríticos. A. Clasificación TAS (Le Bas et al., 1986). B. Clasificación de rocas porfiríticas (Winchester y Floyd, 1977). C. Clasificación de rocas subalcalinas (Peccerillo y Tylor, 1976). E. y F. Discriminación Tectónica (Pearce et al., 1984). GAV: Granitos de Arco Volcánico. G. Diagrama de Martin (1999) para rocas adakiticas. H. Diagrama de Defant y Drummond (1990) para adakitas. 
Respecto a las tierras raras en el sector Alto Los Volcanes se observan dos tendencias (Figura 9A). La primera presenta valores de LREE dada por la relación $(\mathrm{La} / \mathrm{Sm})_{\mathrm{N}}$ entre 7,655 y 11,522 y para las HREE de $(\mathrm{Gd} / \mathrm{Yb})_{\mathrm{N}}$ entre 0,626 y 1,058 con anomalía positiva de $\mathrm{Eu}_{\mathrm{N}} /\left(\mathrm{Sm}_{\mathrm{N}} * \mathrm{Gd}_{\mathrm{N}}\right)^{1 / 2}$ entre 3,042 y 3,840. El segundo grupo presentan relación $(\mathrm{La} / \mathrm{Sm})_{\mathrm{N}}$ entre 6,20 y 7,00 y de $(\mathrm{Gd} / \mathrm{Yb})_{\mathrm{N}}$ entre 1,46 y 2,318 con una anomalía igualmente positiva pero con un valor de $\mathrm{Eu}_{\mathrm{N}} /$ $\left(\mathrm{Sm}_{\mathrm{N}} * \mathrm{Gd}_{\mathrm{N}}\right)^{1 / 2}$ entre 1,32 y 1,48 .

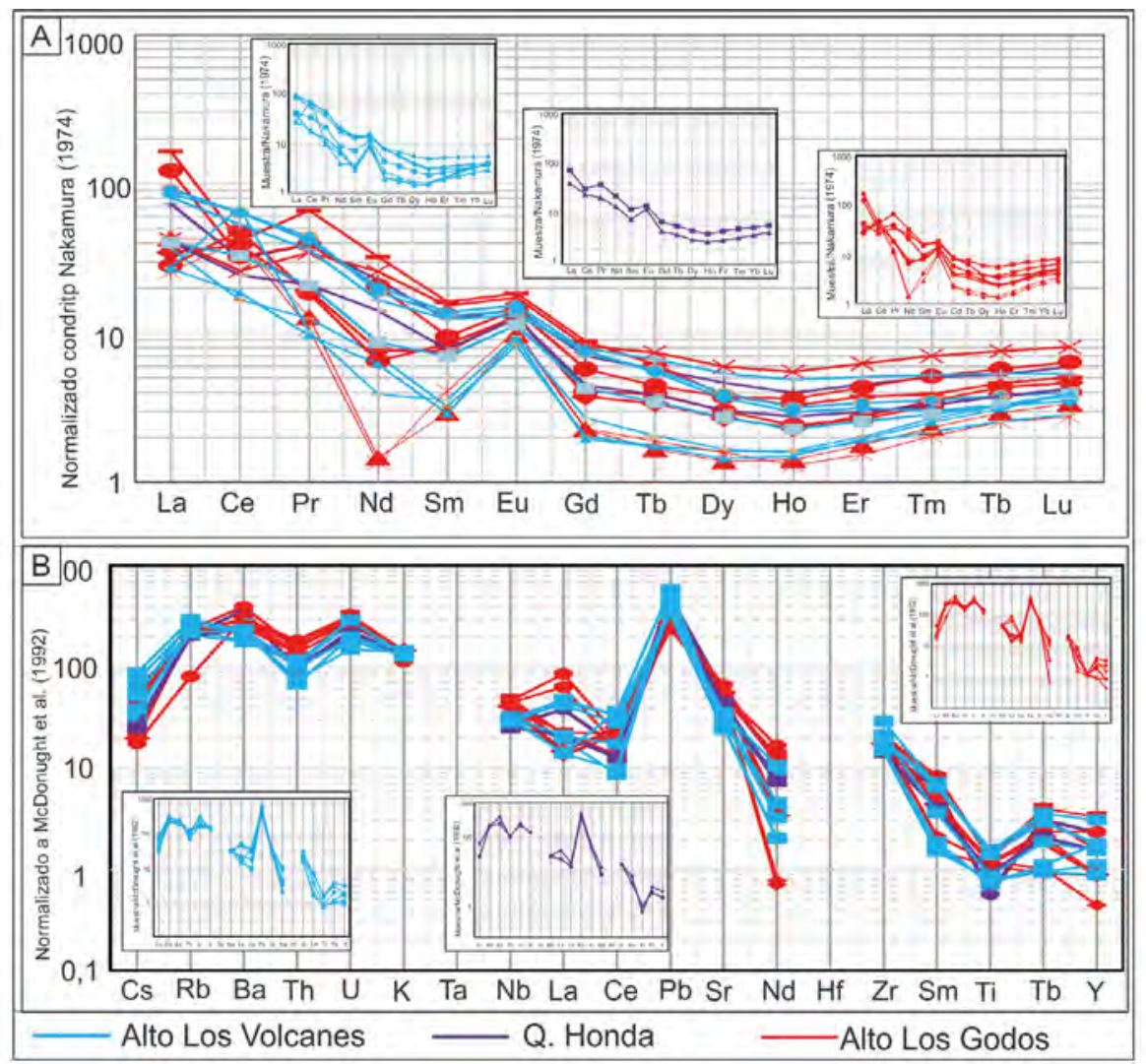

Figura 9. Diagramas de REE y elementos traza. A. Patrón elementos traza normalizados respecto a condrita de Nakamura (1974). B. Patrón Elementos menores normalizados a los valores de manto primitivo de McDonough et al. (1992). Las miniaturas representan los diagramas por sectores.

Las muestras del sector Quebrada Honda (Figura 9) presentan una relación de $(\mathrm{La} / \mathrm{Sm})_{\mathrm{N}}$ y $(\mathrm{Gd} / \mathrm{Yb})_{\mathrm{N}}$ entre 5,215 a 5,944 y 1,193 a 1,313, respectivamente. La anomalía positiva de Eu muestra un valor de $\mathrm{Eu}_{\mathrm{N}} /$ $\left(\mathrm{Sm}_{\mathrm{N}}{ }^{*} \mathrm{Gd}_{\mathrm{N}}\right)^{1 / 2}$ entre 1,557 a 2,110.

Para el sector del Alto Los Godos (Figura 9A) la relación de LREE dada por $(\mathrm{La} / \mathrm{Sm})_{\mathrm{N}}$ está entre 10,201 y 14,726 para un grupo de muestras y de 2,775 y 6,240 para el otro, mientras que las HREE se muestran constantes para todas las muestras con valores de $(\mathrm{Gd} / \mathrm{Yb})_{\mathrm{N}}$ entre 0,866 y 1 con un solo valor de 1,9. Se observa una anomalía positiva en la relación $\mathrm{Eu}_{\mathrm{N}} /\left(\mathrm{Sm}_{\mathrm{N}}{ }^{*} \mathrm{Gd} \mathrm{N}_{\mathrm{N}}\right)^{1 / 2}$ de entre 1,54 a 2,492. Para dos muestras (JR-082 y JR097) se observa una relación más alta de 3,782 y 3,393, respectivamente. Estas dos muestras son las que más se salen del rango respecto a las cantidades de REE de las demás, pero aun así mantiene una tendencia.

El diagrama multivariable con elementos menores (Figura 9B) muestra anomalías positivas de $\mathrm{Pb}$ y ligeramente de $\mathrm{Ba}$ y $\mathrm{U}$, además de una anomalía negativa para el $\mathrm{Ti}$, lo que en principio muestra una firma de rocas de arcos magmático. La tendencia se mantiene en todas las muestras con algunas variaciones de los contenidos de La, Y y Nb. 


\section{Química mineral y termometría}

Dos muestras correspondientes a los domos del Alto Los Godos (JR-047) y al domo de Quebrada Honda (JR-045) fueron analizadas en el borde y núcleo de cristales de feldespato, plagioclasa y anfíbol, teniendo presente las zonaciones y texturas de los cristales (Figura 10B, 10C; Tabla 3 y 4).

Tabla 3. Resultados química mineral en anfíboles y feldespatos en la muestra JR-047, sector Alto Los Godos. Valores en ppm.

\begin{tabular}{|c|c|c|c|c|c|c|c|c|c|c|c|}
\hline \multicolumn{12}{|c|}{ Anfíboles } \\
\hline $\mathrm{Na}_{2} \mathrm{O}$ & MgO & $\mathrm{Al}_{2} \mathrm{O}_{3}$ & $\mathrm{SiO}_{2}$ & $\mathrm{TiO}_{2}$ & $\mathrm{CaO}$ & $\mathrm{K}_{2} \mathrm{O}$ & $\mathrm{FeO}$ & $\mathrm{MnO}$ & $\mathrm{Cr}_{2} \mathrm{O}_{3}$ & Total & Análisis \\
\hline 4,335 & 13,905 & 2,52 & 50,021 & 0,475 & 8,124 & 0,956 & 14,883 & 1,04 & $-0,046$ & 96,213 & 47-1-Amp1-1 \\
\hline 4,598 & 14,664 & 1,766 & 51,081 & 0,468 & 8,121 & 0,86 & 14,285 & 1,032 & $-0,009$ & 96,866 & 47-1-Amp1-3 \\
\hline 4,807 & 14,559 & 1,63 & 50,884 & 0,403 & 7,704 & 0,968 & 14,617 & 1,018 & 0,013 & 96,603 & 47-1-Amp4-1 \\
\hline 4,731 & 14,343 & 1,583 & 51,264 & 0,374 & 7,56 & 0,899 & 14,479 & 1,051 & $-0,028$ & 96,256 & 47-1-Amp4-2 \\
\hline 4,718 & 14,882 & 2,202 & 51,077 & 0,482 & 8,162 & 0,861 & 15,528 & 1,01 & $-0,036$ & 98,886 & $\begin{array}{c}\text { 47-1-Amp3- } \\
1^{*}\end{array}$ \\
\hline 4,584 & 14,84 & 1,581 & 51,213 & 0,444 & 7,708 & 0,884 & 15,12 & 1,035 & $-0,022$ & 97,387 & $\begin{array}{c}\text { 47-1-Amp3- } \\
2 *\end{array}$ \\
\hline 4,615 & 14,233 & 1,942 & 50,796 & 0,458 & 8,025 & 0,909 & 15,671 & 0,98 & $-0,003$ & 97,626 & $\begin{array}{c}\text { 47-1-Amp1- } \\
2^{*}\end{array}$ \\
\hline 4,643 & 14,297 & 1,314 & 50,752 & 0,35 & 7,269 & 0,966 & 16,075 & 1,089 & $-0,011$ & 96,744 & 47-1-Amp5-1 \\
\hline 4,853 & 14,065 & 1,376 & 51,09 & 0,369 & 7,148 & 0,902 & 16,484 & 1,056 & $-0,022$ & 97,321 & 47-1-Amp5-2 \\
\hline \multicolumn{12}{|c|}{ Plagioclasas } \\
\hline $\mathrm{Na}_{2} \mathrm{O}$ & MgO & $\mathrm{Al}_{2} \mathrm{O}_{3}$ & $\mathrm{SiO}_{2}$ & $\mathrm{CaO}$ & $\mathrm{TiO}_{2}$ & $\mathrm{~K}_{2} \mathbf{O}$ & $\mathrm{FeO}$ & MnO & $\mathrm{Cr}_{2} \mathrm{O}_{3}$ & Total & Análisis \\
\hline 10,605 & $-0,075$ & 20,609 & 66,426 & 1,365 & $-0,082$ & 0,84 & 0,079 & 0,006 & $-0,007$ & 99,766 & 047-1-Pl2-1 \\
\hline 10,747 & $-0,065$ & 20,087 & 67,622 & 0,999 & $-0,084$ & 0,998 & 0,134 & $-0,011$ & $-0,017$ & 100,41 & 047-1-Pl2-2 \\
\hline 10,497 & $-0,063$ & 20,107 & 67,798 & 0,695 & $-0,062$ & 1,451 & 0,199 & $-0,005$ & $-0,012$ & 100,605 & 047-1-Pl3-1 \\
\hline 10,403 & $-0,062$ & 20,194 & 67,26 & 0,827 & $-0,06$ & 1,372 & 0,188 & 0 & 0 & 100,122 & 047-1-Pl3-2 \\
\hline \multicolumn{12}{|c|}{ F. Potásico } \\
\hline $\mathrm{Na}_{2} \mathrm{O}$ & MgO & $\mathrm{SiO}_{2}$ & $\mathrm{Al}_{2} \mathrm{O}_{3}$ & $\mathrm{CaO}$ & $\mathrm{TiO}_{2}$ & $\mathrm{~K}_{2} \mathrm{O}$ & $\mathrm{FeO}$ & $\mathrm{MnO}$ & $\mathrm{Cr}_{2} \mathrm{O}_{3}$ & Total & Análisis \\
\hline 8,164 & $-0,059$ & 65,96 & 19,497 & 0,082 & $-0,06$ & 4,895 & 0,308 & $-0,014$ & 0,01 & 98,783 & 047-1-Fks1-1 \\
\hline 8,553 & $-0,051$ & 66,693 & 19,469 & 0,082 & $-0,061$ & 4,591 & 0,445 & 0,007 & $-0,006$ & 99,722 & 047-1-Fks1-2 \\
\hline 8,589 & $-0,057$ & 66,732 & 19,575 & 0,072 & $-0,062$ & 4,865 & 0,433 & 0,005 & $-0,015$ & 100,137 & $\begin{array}{c}047-1-F k s 1.2- \\
1\end{array}$ \\
\hline 8,21 & $-0,043$ & 67,09 & 19,475 & 0,054 & $-0,054$ & 4,872 & 0,395 & $-0,007$ & $-0,011$ & 99,981 & $\begin{array}{c}\text { 047-1-Fks1.2- } \\
2\end{array}$ \\
\hline 8,435 & $-0,063$ & 65,643 & 19,624 & 0,266 & $-0,052$ & 4,155 & 0,3 & $-0,023$ & $-0,019$ & 98,266 & 047-1-Fks3-1 \\
\hline 8,657 & $-0,057$ & 66,673 & 19,72 & 0,058 & $-0,077$ & 4,23 & 0,466 & 0,008 & $-0,016$ & 99,662 & 047-1-Fks3-2 \\
\hline 8,446 & $-0,058$ & 65,7 & 19,847 & 0,205 & $-0,059$ & 4,403 & 0,281 & $-0,012$ & $-0,02$ & 98,733 & 047-1-Fks3-3 \\
\hline 8,902 & $-0,063$ & 66,561 & 19,312 & 0,108 & $-0,062$ & 4,272 & 0,305 & $-0,002$ & $-0,006$ & 99,327 & 047-1-Fks4-1 \\
\hline 8,625 & $-0,06$ & 65,987 & 19,538 & 0,102 & $-0,059$ & 4,373 & 0,293 & $-0,017$ & $-0,013$ & 98,769 & 047-1-Fks4-2 \\
\hline 8,323 & $-0,054$ & 66,344 & 19,12 & 0,047 & $-0,059$ & 4,899 & 0,396 & 0 & $-0,001$ & 99,015 & 047-1-Fks4-3 \\
\hline 8,577 & $-0,053$ & 66,259 & 19,326 & 0,131 & $-0,034$ & 4,445 & 0,337 & $-0,005$ & $-0,01$ & 98,973 & 047-1-Fks4-4 \\
\hline 8,501 & $-0,065$ & 66,174 & 19,545 & 0,271 & $-0,047$ & 4,229 & 0,223 & $-0,024$ & $-0,011$ & 98,796 & 047-1-Pl'1-1 \\
\hline 8,558 & $-0,06$ & 66,125 & 19,443 & 0,208 & $-0,068$ & 4,259 & 0,2 & 0,012 & $-0,017$ & 98,66 & 047-1-Pl'1-2 \\
\hline 8,65 & $-0,057$ & 66,128 & 19,608 & 0,145 & $-0,057$ & 4,276 & 0,262 & $-0,01$ & 0,005 & 98,95 & 047-1-Pl'1-3 \\
\hline
\end{tabular}


Tabla 4. Resultados química mineral en anfíbol y feldespato en la muestra JR-045, sector Quebrada Honda. Valores en ppm.

\begin{tabular}{|c|c|c|c|c|c|c|c|c|c|c|c|}
\hline \multicolumn{12}{|c|}{ Anfíbol } \\
\hline $\mathrm{Na}_{2} \mathrm{O}$ & MgO & $\mathrm{Al}_{2} \mathrm{O}_{3}$ & $\mathrm{SiO}_{2}$ & $\mathrm{TiO}_{2}$ & $\mathrm{CaO}$ & $\mathbf{K}_{2} \mathbf{O}$ & $\mathrm{FeO}$ & MnO & $\mathrm{Cr}_{2} \mathrm{O}_{3}$ & Total & Análisis \\
\hline 2,535 & 9,913 & 15,074 & 41,602 & 1,272 & 10,334 & 1,146 & 15,989 & 0,247 & 0,017 & 98,129 & 45-1-Amp2-1 \\
\hline 2,579 & 10,082 & 15,108 & 42,046 & 1,358 & 10,36 & 0,929 & 16,235 & 0,268 & 0,003 & 98,968 & 45-1-Amp2-2 \\
\hline 2,614 & 10,282 & 17,621 & 41,617 & 0,893 & 10,53 & 1,254 & 14,532 & 0,051 & $-0,021$ & 99,373 & 45-1-Amp4-1 \\
\hline 2,838 & 11,19 & 13,414 & 41,419 & 1,067 & 10,555 & 1,276 & 16,382 & 0,254 & $-0,049$ & 98,346 & 45-1-Amp4-2 \\
\hline 4,693 & 13,399 & 1,704 & 50,997 & 0,431 & 6,883 & 0,951 & 16,142 & 1,783 & $-0,024$ & 96,959 & 45-1-Amp3-1 \\
\hline 4,734 & 13,728 & 1,159 & 51,202 & 0,285 & 6,639 & 0,99 & 15,503 & 1,736 & 0,016 & 95,992 & 45-1-Amp3-2 \\
\hline 4,639 & 13,699 & 0,973 & 50,919 & 0,297 & 6,838 & 0,903 & 16,811 & 1,569 & $-0,018$ & 96,63 & 45-1-Amp5-1* \\
\hline 4,693 & 13,621 & 1,581 & 50,834 & 0,415 & 7,212 & 0,797 & 16,781 & 1,574 & $-0,031$ & 97,477 & 45-1-Amp5-2* \\
\hline 3,172 & 8,584 & 15,786 & 39,79 & 1,132 & 10,083 & 1,036 & 20,286 & 0,291 & $-0,035$ & 100,125 & 45-1-Amp4-1* \\
\hline 3,313 & 8,589 & 16,021 & 40,133 & 1,212 & 10,178 & 1,04 & 20,402 & 0,308 & $-0,032$ & 101,164 & 45-1-Amp4-1* \\
\hline 4,861 & 13,962 & 1,269 & 51,542 & 0,26 & 6,617 & 0,964 & 17,1 & 1,736 & $-0,003$ & 98,308 & 45-1-Amp3-2 \\
\hline 5,136 & 13,659 & 1,149 & 51,645 & 0,295 & 6,714 & 0,976 & 17,368 & 1,575 & $-0,016$ & 98,501 & 45-1-Amp6-1 \\
\hline 5,124 & 13,367 & 1,159 & 51,059 & 0,322 & 6,572 & 0,972 & 17,27 & 1,48 & 0,004 & 97,329 & 45-1-Amp6-2 \\
\hline \multicolumn{12}{|c|}{ Plagioclasas } \\
\hline $\mathrm{Na}_{2} \mathrm{O}$ & MgO & $\mathrm{Al}_{2} \mathrm{O}_{3}$ & $\mathrm{SiO}_{2}$ & $\mathrm{CaO}$ & $\mathrm{TiO}_{2}$ & $\mathrm{~K}_{2} \mathrm{O}$ & $\mathrm{FeO}$ & MnO & $\mathrm{Cr}_{2} \mathrm{O}_{3}$ & Total & Análisis \\
\hline 10,409 & $-0,055$ & 20,791 & 66,452 & 1,258 & $-0,049$ & 0,984 & 0,108 & $-0,02$ & $-0,002$ & 99,876 & 045-1-Pl2-1 \\
\hline 10,16 & $-0,05$ & 20,824 & 65,86 & 1,354 & $-0,091$ & 1,141 & 0,106 & $-0,012$ & $-0,008$ & 99,284 & 045-1-Pl2-2 \\
\hline 8,679 & $-0,078$ & 18,65 & 66,67 & 0,054 & $-0,07$ & 4,445 & 0,377 & 0,006 & 0,011 & 98,744 & 045-1-Pl2-3 \\
\hline 10,461 & $-0,057$ & 20,487 & 67,507 & 1,104 & $-0,068$ & 0,983 & 0,142 & $-0,003$ & 0,01 & 100,566 & 045-1-Pl3-1 \\
\hline 10,72 & $-0,036$ & 20,356 & 68,726 & 0,723 & $-0,065$ & 1,123 & 0,173 & $-0,02$ & $-0,002$ & 101,698 & 045-1-Pl3-2 \\
\hline 8,469 & $-0,069$ & 18,674 & 67,39 & 0,071 & $-0,083$ & 4,57 & 0,343 & $-0,002$ & $-0,008$ & 99,355 & 045-1-Pl3-3 \\
\hline 10,576 & $-0,065$ & 20,429 & 67,532 & 1,265 & $-0,058$ & 0,885 & 0,1 & $-0,004$ & $-0,011$ & 100,649 & 045-1-Pl4-1 \\
\hline 9,396 & $-0,075$ & 22,735 & 63,226 & 3,4 & $-0,065$ & 0,556 & 0,102 & $-0,006$ & 0,002 & 99,271 & 045-1-Pl4-2 \\
\hline 10,062 & $-0,059$ & 20,572 & 66,91 & 1,389 & $-0,055$ & 1,294 & 0,188 & $-0,003$ & $-0,024$ & 100,274 & 045-1-Pl4-3 \\
\hline 10,557 & $-0,055$ & 20,592 & 68,449 & 1,142 & $-0,089$ & 1,066 & 0,103 & $-0,029$ & 0,004 & 101,74 & 045-1-Pl5-1 \\
\hline 9,472 & $-0,068$ & 22,539 & 64,362 & 2,883 & $-0,072$ & 0,741 & 0,117 & 0 & $-0,016$ & 99,958 & 045-1-Pl5-2 \\
\hline 8,269 & $-0,079$ & 18,692 & 67,321 & 0,05 & $-0,062$ & 5,025 & 0,369 & 0,006 & 0,001 & 99,592 & 045-1-Pl5-3 \\
\hline 8,715 & $-0,064$ & 23,154 & 62,164 & 3,832 & $-0,03$ & 0,584 & 0,139 & $-0,006$ & 0,001 & 98,489 & 045-1-Pl6-1 \\
\hline 10,151 & $-0,062$ & 19,487 & 67,298 & 0,585 & $-0,066$ & 1,546 & 0,273 & $-0,009$ & $-0,009$ & 99,194 & 045-1-Pl6-2 \\
\hline \multicolumn{12}{|c|}{ F. Potásico } \\
\hline $\mathrm{Na}_{2} \mathrm{O}$ & MgO & $\mathrm{SiO}_{2}$ & $\mathrm{Al}_{2} \mathrm{O}_{3}$ & $\mathrm{CaO}$ & $\mathrm{TiO}_{2}$ & $\mathbf{K}_{2} \mathbf{O}$ & $\mathrm{FeO}$ & MnO & $\mathrm{Cr}_{2} \mathrm{O}_{3}$ & Total & Análisis \\
\hline 10,971 & $-0,058$ & 67,755 & 20,319 & 0,222 & $-0,068$ & 1,376 & 0,287 & $-0,011$ & $-0,038$ & 100,755 & 045-1-Fks4-1 \\
\hline 8,777 & $-0,052$ & 66,591 & 19,463 & 0,063 & $-0,056$ & 4,374 & 0,337 & $-0,005$ & $-0,016$ & 99,476 & 045-1-Fks4-2 \\
\hline 8,946 & $-0,051$ & 66,73 & 19,741 & 0,072 & $-0,059$ & 4,304 & 0,335 & $-0,02$ & $-0,015$ & 99,983 & 045-1-Fks4-3 \\
\hline 8,602 & $-0,064$ & 67,087 & 19,541 & 0,044 & $-0,055$ & 4,478 & 0,415 & $-0,017$ & $-0,012$ & 100,019 & 045-1-Fks3-1 \\
\hline 8,844 & $-0,058$ & 66,741 & 19,373 & 0,081 & $-0,044$ & 4,301 & 0,332 & $-0,027$ & $-0,02$ & 99,523 & 045-1-Fks3-2 \\
\hline 10,022 & $-0,058$ & 66,955 & 18,891 & 0,527 & $-0,072$ & 1,757 & 0,317 & $-0,01$ & $-0,024$ & 98,305 & 045-1-Fks5-1* \\
\hline 8,836 & $-0,061$ & 65,009 & 18,727 & 0,398 & $-0,051$ & 3,241 & 0,35 & $-0,001$ & 0 & 96,448 & 045-1-Fks5-2* \\
\hline
\end{tabular}


Estos análisis confirman lo visto mediante petrografía y permiten definir las especies minerales que conforman las texturas de sobrecrecimiento. Estos resultados demuestran la presencia, al menos para el domo del sector Quebrada Honda (muestra JR-045), de un núcleo de plagioclasa tipo albita (en algunos casos oligoclasa) rodeado de una corona de feldespato tipo anortoclasa (Figura 10A). Para la muestra del Alto Los Godos la plagioclasa se clasifica como albita y el feldespato como anortita (Figura 10A).
Según la clasificación de Leake et al. (1997) la mayoría de los cristales de anfíbol de las dos muestras caen en el límite de la richterita y katoforitas, aunque para la muestra JR-045 dos cristales presentan una variación en la composición quedando en el campo de la hastingsita (Figura 10A). Cabe destacar que los porcentajes de titanio son muy bajos en la mayoría de los casos $(<0,5 \%)$ y se observa una variación entre los contenidos de $\mathrm{Al}_{2} \mathrm{O}_{3}$ de entre 1,3 y 2,5 wt.\% para Quebrada Honda y hasta mayores de 15 wt.\% para el Alto Los Godos.

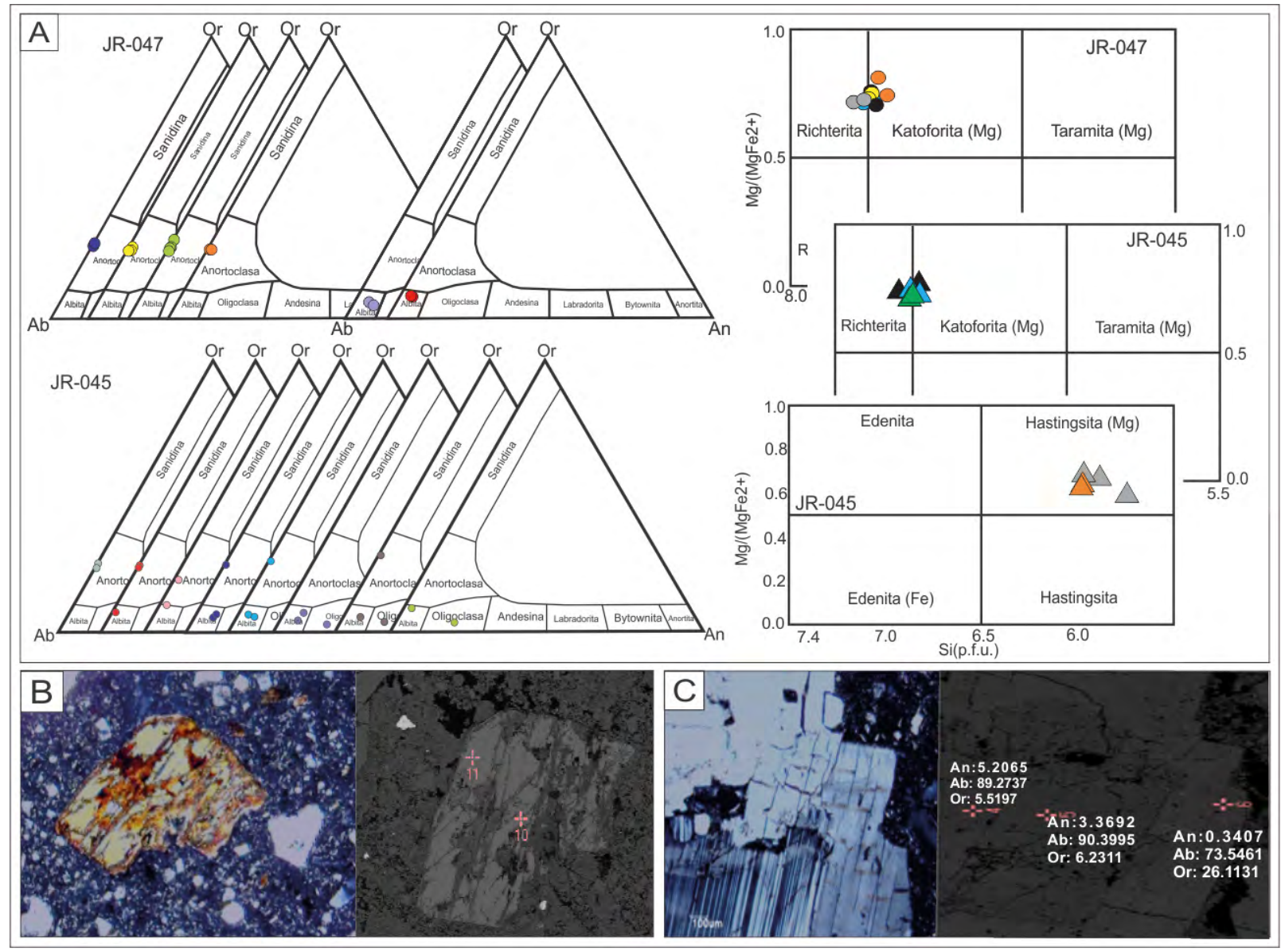

Figura 10. Diagramas de las clasificaciones de feldespatos y anfíboles para dos muestras. A. Clasificación de plagioclasa y diagrama de clasificación de anfíboles según Leake et al. (1997) para parámetro $(\mathrm{Na}+\mathrm{K})_{\mathrm{A}}>0,50 ;\left(\mathrm{Ca}+\mathrm{Na}_{\mathrm{B}}\right)>1,00 ; 0,50<\mathrm{Na}_{\mathrm{B}}<1,50$ y parámetro $\mathrm{Ti}<0,50,(\mathrm{Na}+\mathrm{K})_{\mathrm{A}} \geq 0,50, \mathrm{Ca}_{\mathrm{B}} \geq 1,50$ y Alvi $<\mathrm{Fe}^{3+}$. B. Microfotografía de la ubicación de los análisis en anfíbol. C. Microfotografía de la ubicación de los análisis en una ortoclasa con núcleo de plagioclasa.

A partir de las concentraciones calculadas para los cristales de plagioclasa y anfíbol se calcularon las temperaturas y presión de cristalización aproximadas (Tabla 5). La temperatura mediante el geotermómetro de Ti en anfíbol dio un promedio de $618^{\circ} \mathrm{C}$ teniendo presente el geotermómetro de Otten (1984), pero basados en el geotermómetro de Blundy y Holland
(1990) que involucra el equilibrio anfíbol-plagioclasa la temperatura promedio para las dos muestras es de $675,9^{\circ} \mathrm{C}$.

Las presiones calculadas son de 9,18 kbars, solo halladas para las hastingsitas de la muestra JR-045. Hay que tener en cuenta que el geobarómetro en anfíbol 
está relacionado al contenido de $\mathrm{Al}$ en el cristal, por esta razón, la presión para la muestra JR-047 y algunos cristales de la muestra JR-045 no fue posible calcularla usando los geobarómetros mostrados en la Tabla 5, cuyos valores de $\mathrm{Al}$ son menores a 2,5. Usando el geobarómetro anfíbol-plagioclasa Blundy y Holland (1990) no mostrado en la Tabla 5, las presiones sobrepasan los 10 kbars.

Tabla 5. Resultados termobarométricos.

\begin{tabular}{|c|c|c|c|c|c|c|c|c|c|c|c|c|c|}
\hline \multicolumn{14}{|c|}{ Temperatura $\left({ }^{\circ} \mathrm{C}\right)$} \\
\hline \multirow{6}{*}{$\begin{array}{l}\text { (Otten, } \\
1984)^{*}\end{array}$} & \multicolumn{13}{|c|}{ JR-045 } \\
\hline & $\begin{array}{c}\text { Amp2- } \\
1\end{array}$ & $\begin{array}{c}\text { Amp2- } \\
2\end{array}$ & $\begin{array}{c}\text { Amp4- } \\
1\end{array}$ & $\begin{array}{c}\text { Amp4- } \\
2\end{array}$ & Amp3-1 & Amp3-2 & $\begin{array}{c}\text { Amp5- } \\
1^{*}\end{array}$ & $\begin{array}{c}\text { Amp5- } \\
2^{*}\end{array}$ & $\begin{array}{c}\text { Amp4- } \\
1^{*}\end{array}$ & Amp3-2 & Amp6-1 & Amp6-2 & Promedio \\
\hline & 714,6 & 724,1 & 661,5 & 687,5 & 603,8 & 584,1 & 586,0 & 601,7 & 695,3 & 580,3 & 585,0 & 589,1 & 634,4 \\
\hline & \multicolumn{13}{|c|}{ JR-047 } \\
\hline & $\begin{array}{l}\text { Amp1- } \\
1\end{array}$ & $\underset{3}{\text { Amp1- }}$ & $\begin{array}{c}\text { Amp4- } \\
1\end{array}$ & $\begin{array}{l}\text { Amp4- } \\
2\end{array}$ & $\begin{array}{l}\text { Amp3- } \\
1^{*}\end{array}$ & $\begin{array}{l}\text { Amp3- } \\
2^{*}\end{array}$ & $\begin{array}{l}\text { Amp1- } \\
2^{*}\end{array}$ & Amp5-1 & Amp5-1 & -- & -- & -- & \\
\hline & 609,5 & 608,6 & 600 & 595,8 & 609,3 & 605,1 & 606,6 & 592,5 & 594,6 & -- & -- & -- & 602,4 \\
\hline \multirow{4}{*}{$\begin{array}{l}\text { Blundy y } \\
\text { Holland } \\
(1990)^{* *}\end{array}$} & \multicolumn{13}{|c|}{ JR-045 } \\
\hline & 626,8 & 635,7 & 471,1 & 662,9 & 663,5 & 522,0 & 762,6 & 856,7 & 705,6 & 748,1 & 872,2 & 529,8 & 671,4 \\
\hline & \multicolumn{13}{|c|}{ JR-047 } \\
\hline & 722,6 & 680,8 & 676,7 & 676,5 & 538,0 & 745,5 & 728,5 & 747,3 & -- & -- & -- & -- & 680,7 \\
\hline \multicolumn{14}{|c|}{ Presión (kbars)*** } \\
\hline \multicolumn{14}{|c|}{ JR-045 } \\
\hline \multicolumn{2}{|c|}{ Muestra/punto } & \multicolumn{2}{|c|}{ Amp2-1 } & \multicolumn{2}{|c|}{ Amp2-2 } & \multicolumn{2}{|c|}{ Amp4-1 } & \multicolumn{2}{|c|}{ Amp4-2 } & \multicolumn{2}{|c|}{ Amp4-1* } & -- & -- \\
\hline \multicolumn{2}{|c|}{$\begin{array}{c}\text { Hammarstrom y Zen } \\
\text { (1986) }\end{array}$} & \multicolumn{2}{|c|}{9,2} & \multicolumn{2}{|c|}{9,1} & \multicolumn{2}{|c|}{11,1} & \multicolumn{2}{|c|}{7,7} & \multicolumn{2}{|c|}{9,7} & -- & -- \\
\hline \multicolumn{2}{|c|}{ Hollister et al. (1987) } & \multicolumn{2}{|c|}{9,9} & & 8 & \multicolumn{2}{|c|}{12,1} & \multicolumn{2}{|c|}{8,3} & \multicolumn{2}{|c|}{10,5} & -- & -- \\
\hline \multicolumn{2}{|c|}{$\begin{array}{c}\text { Johnson y Rutherford } \\
\text { (1989) }\end{array}$} & \multicolumn{2}{|c|}{7,6} & & 5 & \multicolumn{2}{|c|}{9,2} & \multicolumn{2}{|c|}{6,4} & \multicolumn{2}{|c|}{8,0} & -- & -- \\
\hline \multicolumn{2}{|c|}{ Schmidt (1992) } & \multicolumn{2}{|c|}{9,4} & & 3 & & & & 0 & & & -- & -- \\
\hline Pro & & & 0 & & & & & & 6 & & & -- & -- \\
\hline
\end{tabular}

*Geotermómetro de Ti en anfíbol

**Geotermómetro basado en equilibrio anfíbol-plagioclasa

***Geobarómetro de $\mathrm{Al}$ en anfíbol

\section{Dataciones Ar-Ar}

Cinco muestras de los cuerpos dómicos fueron datadas mediante Ar-Ar en cristales de hornblenda, sanidina y feldespato. La edad Plateau se muestra en la Figura 11 y los resultados se resumen en la Tabla 6 .

Así, es posible visualizar que el emplazamiento de uno de los cuerpos del Alto Los Volcanes (Domos Olitas) se dio hace 1,8 $\pm 0,03$ Ma como lo indica la edad en un cristal de sanidina, al igual que el emplazamiento de uno de los cuerpos del sector Quebrada Honda el cual

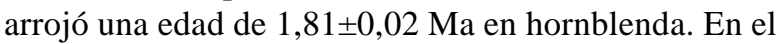

sector del Alto Los Godos, los cuerpos datados (Domo Matarredonda, Domo Central y Domo SE) a partir de cristales de feldespato y plagioclasa, arrojaron edades de 2,71 $\pm 0,024,2,8 \pm 0,031$ y 2,70 $\pm 0,018 \mathrm{Ma}$, respectivamente, lo que indica el mismo evento para el emplazamiento de los domos de este sector. Además de los cuerpos que conforman el complejo de domos de Paipa, fue datada una muestra perteneciente a uno de los domos de Iza, cuerpo localizado a aproximadamente $23 \mathrm{~km}$ al SE de Paipa. El resultado arrojó una edad de $6 \pm 0,06 \mathrm{Ma}$ en cristales de feldespato. 


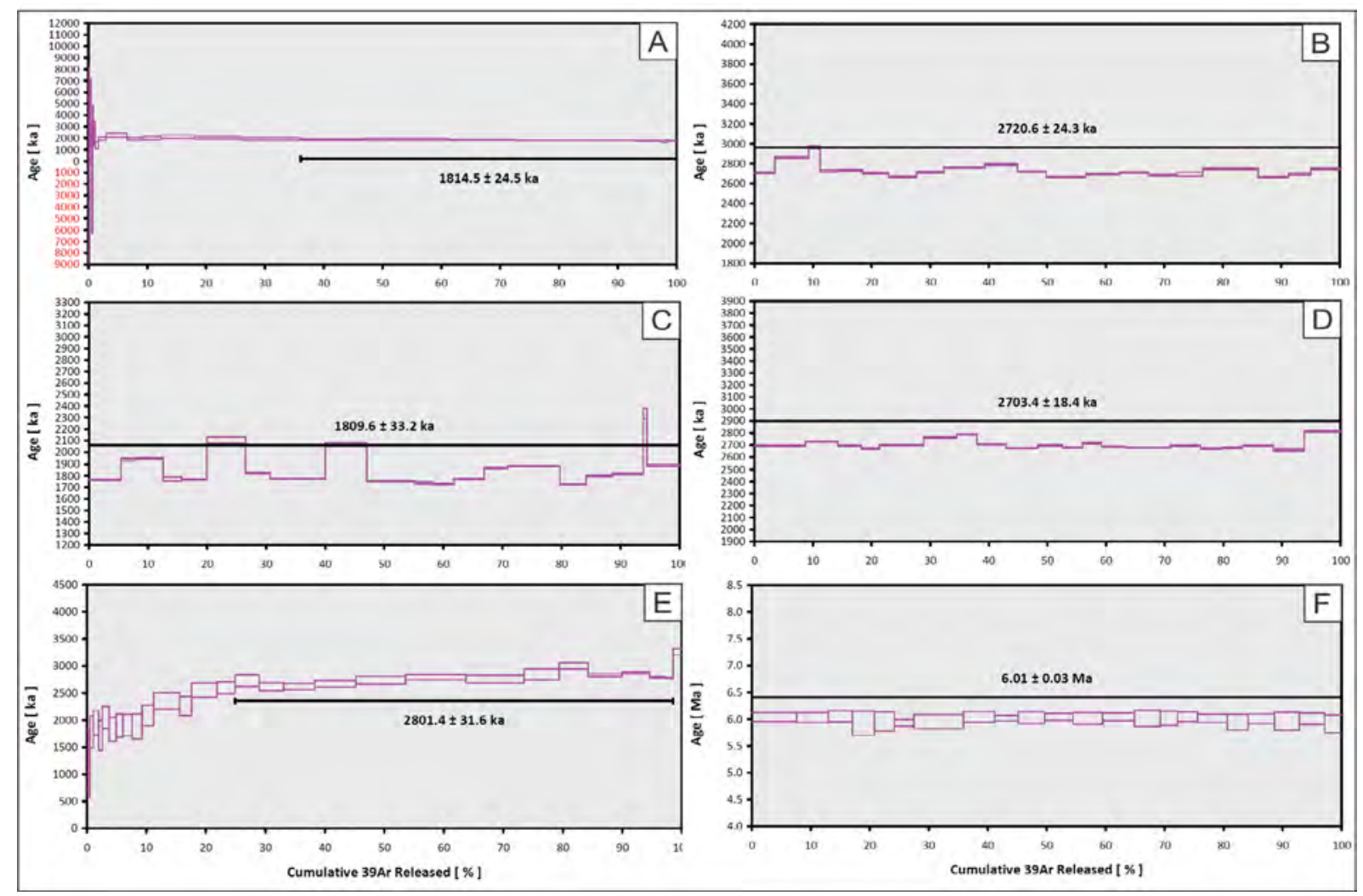

Figura 11. Diagramas de Plateau para muestras datadas. A. Domo Iza, muestra JR-044-1. B. Domo Quebrada Honda, muestra PAJR-045-1. C. Domo Alto Los Godos, muestra JR-047-1. D. Domo Alto Los Volcanes, muestra JR-052-1. E. Domo SE Alto Los Godos, muestra JR-116-1. F. Domo Central Alto Los Godos, muestra JR-050-1.

Tabla 6. Edades Ar-Ar para los cuerpos dómicos de Paipa.

\begin{tabular}{ccccccc}
\hline Muestra & Latitud & Longitud & $\begin{array}{c}\text { Edad Plateau } \\
\text { (Ma) }\end{array}$ & $\begin{array}{c}\text { Edad Ideograma } \\
\text { (Ma) }\end{array}$ & Mineral & Localización \\
\hline JR-045-1 & 5,7056 & $-73,1079$ & $1,81 \pm 0,024$ & --- & Hornblenda & Domo Quebrada Honda \\
JR-052-1 & 5,6948 & $-73,1134$ & $1,8 \pm 0,033$ & $1,76 \pm 0,002$ & Sanidina & Domo Olitas (Alto Los Volcanes) \\
JR-047-1 & 5,7176 & $-73,0949$ & $2,72 \pm 0,024$ & $2,71 \pm 0,0025$ & Feldespato & Domo Matarredonda (Alto Los \\
JR-050-1 & 5,7125 & $-73,1011$ & $2,80 \pm 0,031$ & --- & Podos) \\
JR-116-4-B & 5,7029 & $-73,0901$ & $2,7 \pm 0,018$ & $2,6 \pm 0,0021$ & Sanidina & Domo SE (Alto Los Godos) \\
\hline
\end{tabular}

\section{Evidencia de otras estructuras intrusivas}

Además del cuerpo de El Durazno ya antes reconocido (ENUSA-IAN, 1979; Ferreira y Hernández, 1988; González et al., 2008), en el área de estudio se pueden reconocer geomorfológicamente algunas otras estructuras que se asemejan a intrusiones dómicas (Figura 12A y 12B) y que junto con los resultados geofísicos mostrados en Beltrán (2015) resaltan la hipótesis de que se traten de intrusiones. Uno de estos sectores es justo al norte del área de estudio en el sector conocido como ITP-Lanceros y donde se presenta la mayor zona de descarga de aguas termales (Figura 1). Aquí se evidencia una elevación de $2522 \mathrm{msnm}$ sobre una planicie de $2490 \mathrm{msnm}$ dada por depósitos cuaternarios al oeste y de $2514 \mathrm{msnm}$ al este dada por la topografía inclinada de las unidades sedimentarias. Coincidiendo con esta elevación, controlada probablemente por la falla El Bizcocho, se observa una anomalía gravimétrica (Figura 12C) positiva con una forma perfectamente redonda. El control de campo en este punto, muestra una litología sedimentaria con los estratos y depósitos de la Formación Tilatá curvados. 
Si bien ninguna evidencia litología de naturaleza intrusiva se encontró, es posible que dicha estructura sea producto del levantamiento por una intrusión en el subsuelo como se observa en la Figura 12D.

Al sureste del área de estudio, sobre el flanco del anticlinal de Tibasosa - Toledo, en el sector conocido como cerro Las Cruces, resaltan dos geoformas cóncavas de la topografía inclinada al sur, pero relativamente homogénea (Figura 12E - 12H), alineadas en dirección NW-SE, similar a la orientación de los domos del Alto Los Godos. Los recorridos de campo mostraron una litología sedimentaria correspondiente a niveles arenosos con intercalaciones de lodolitas que buzan al norte, concordando con la dirección del flanco del anticlinal y, no se presenta ninguna evidencia de roca volcánica. La evidencia al igual que para el cuerpo del sector ITP-Lanceros, es soportada por la geomorfología y las anomalías gravimétricas que se registran en este sector (Figura 12G).

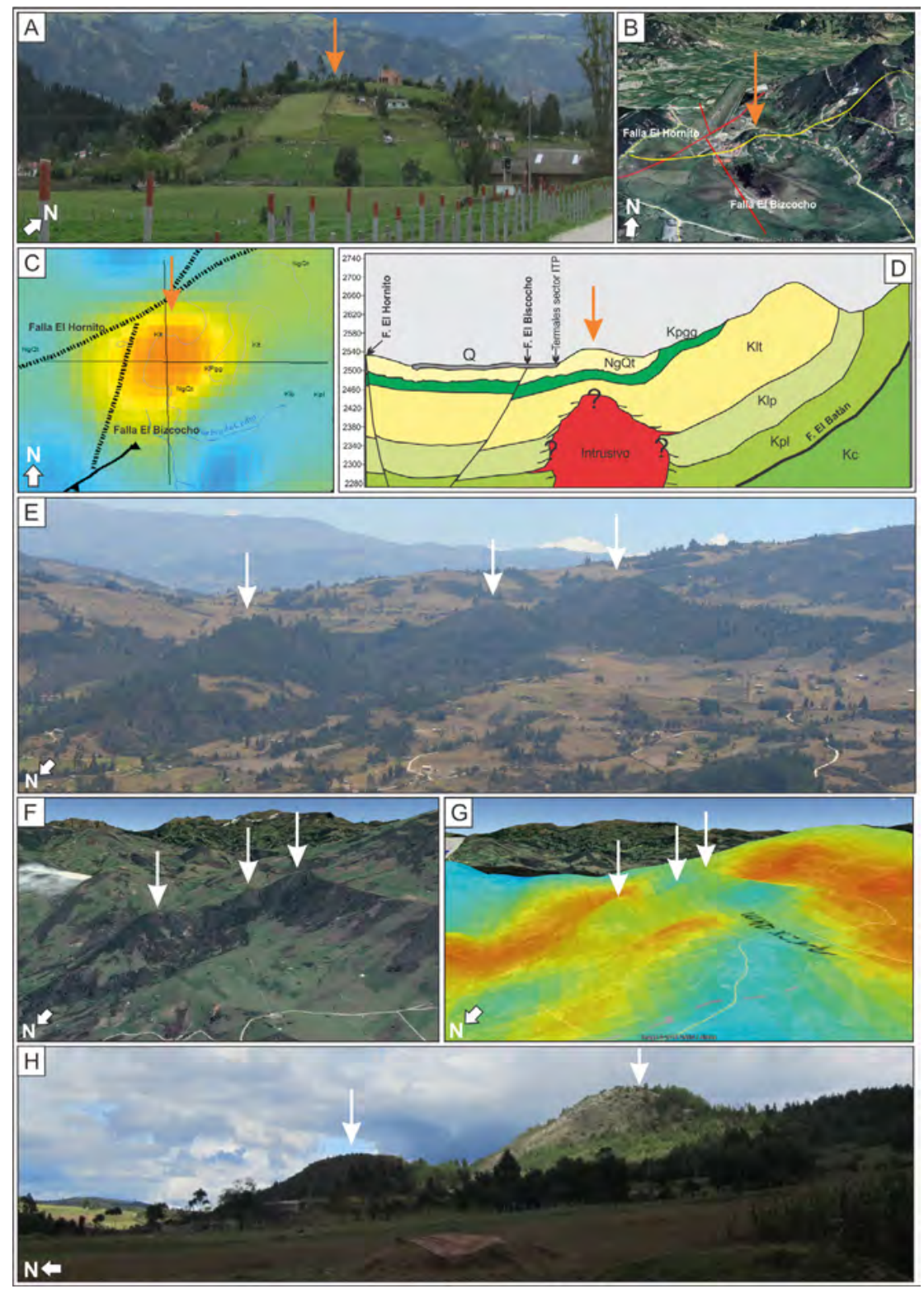

Figura 12. Evidencias de posibles estructuras intrusivas. A. B. Fotografías de geoformas dómicas en el sector ITP-Lanceros (Paipa). C. Anomalía de gravedad en el mismo lugar. D. Corte idealizado representando la disposición de los estratos, debido a la intrusión magmática. E. Fotografías de las geoformas dómicas al sur del área de estudio, flanco occidental del anticlinal Tibasosa-Toledo. F. Imagen Google Earth mostrando la ubicación de los tres picos vistos en E. G. Misma imagen de F con la grilla de gravimetría (anomalía residual) mostrada en Beltrán (2015). H. Fotografía con vista desde el oeste donde mejor se observan las posibles formas dómicas dadas por intrusiones. 


\section{Discusión}

\section{Correlaciones de campo}

La evidencia en campo de nuevos afloramientos expuestos en el sector del Alto Los Godos, específicamente en el criptodomo de Matarredonda, permitió ver un contacto entre depósitos volcánicos y el criptodomo (Figura 13A) dada su forma irregular entre los depósitos volcánicos y la intrusión, lo cual hace suponer un emplazamiento de los domos posterior a la depositación de los productos eruptivos. Otro punto donde mejor se ve la correlación entre los depósitos y la roca es en el domo SE del sector Alto
Los Godos. En este punto claramente se controla el contacto entre depósitos piroclásticos arriba y la roca intrusiva abajo (Figura 13B). Además, se ve claramente cómo se expone a manera de intrusión en los depósitos piroclásticos, la roca claramente porfirítica, dejando ver a lado y lado de la intrusión, los depósitos con una tonalidad rojiza producto del contacto de la intrusión (Figura 13C). Continuando por el mismo camino, en una cantera, hasta ese momento abandona, se expone nuevamente un claro contacto entre depósitos rojizos y el domo (Figura 13D) con algunas brechas asociadas al borde del domo.
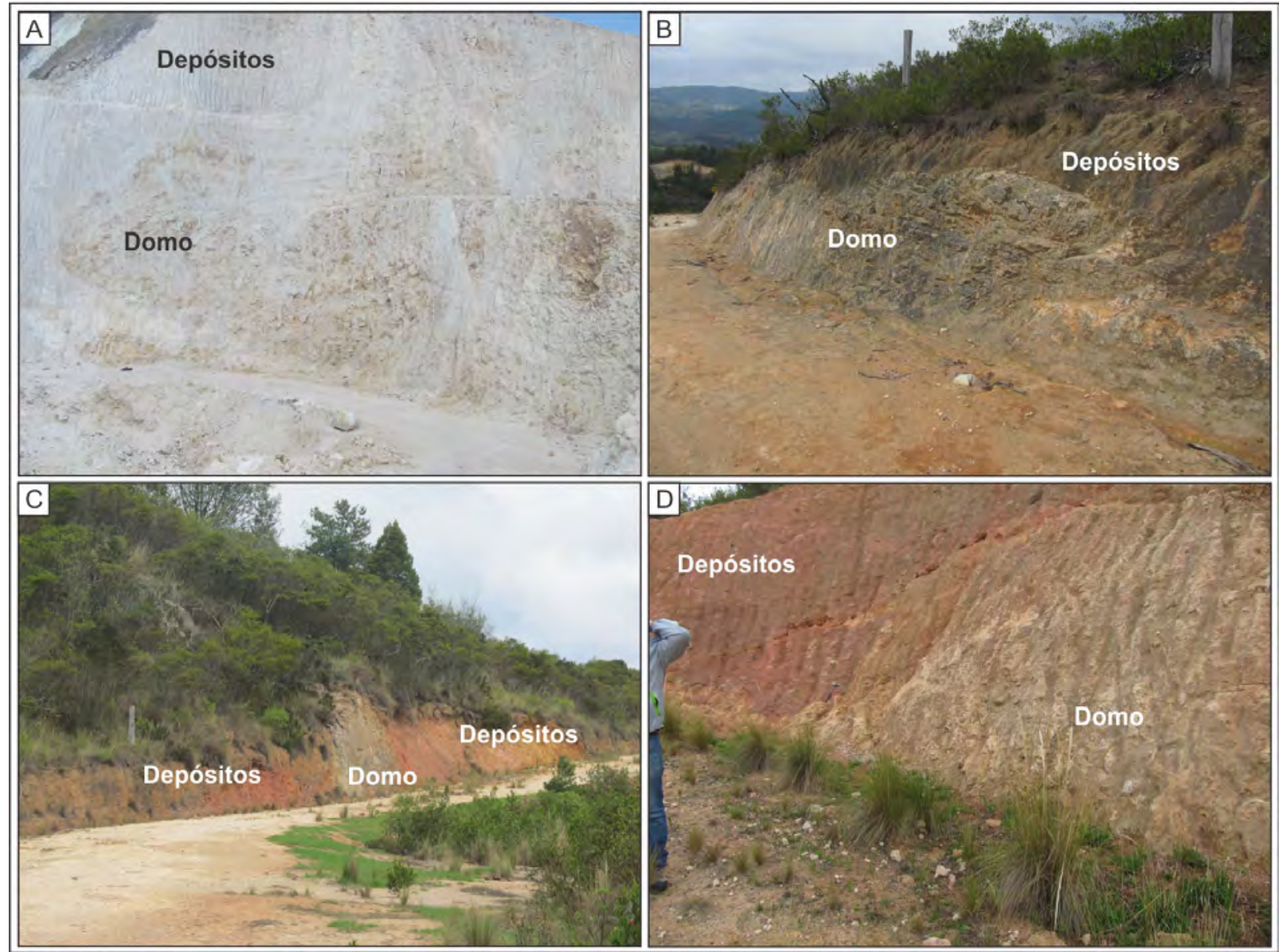

Figura 13. Relaciones temporales de campo. A. Contacto sinuoso entre el domo y los depósitos piroclásticos. B. Entrada a la cantera del domo SE. C. Intrusión del domo SE en depósitos. D. Depósitos rojizos en contacto con el domo SE.

\section{Roca coherente vs depósitos}

En Cepeda y Pardo (2004) se describen las unidades del volcán de Paipa detalladamente donde propone la unidad I1 haciendo referencia a un depósito mal seleccionado de cenizas cristalinas y vidrio, altamente soldado, originado por colapso de columnas. Esta unidad es dividida en un segmento basal y un segmento superior identificada tanto en el sector del Alto Los Godos como en el Alto Los Volcanes. Los autores hacen referencia al segmento basal como "depósito soldado de ceniza rico en cristales, de aspecto masivo, no estratificado, mal seleccionado" y el segmento 
superior como "conjunto de capas rojas piroclásticas, de espesor variable ( 1 metro en promedio) poco litificado, muy alterado, mal seleccionado, de cenizas gruesas y fragmentos líticos tamaño lapilli". Si bien la unidad superior efectivamente aflora en estos lugares, al menos en el Alto Los Godos, lo que se plantea en este trabajo y, retomando los trabajos anteriores, es que el segmento basal no haría referencia a un depósito piroclástico, sino más bien a roca porfirítica (domo). Dicha correlación entre los domos y depósitos volcánicos, sería originada por la alta meteorización de la roca en algunos lugares la cual hace que los cristales sean destruidos por completo. Por otro lado, los autores especifican el carácter piroclástico por la presencia de "microshards" en la muestra, con una clasificación textural de cristalina y cristalo-vitrea, pero claramente, la removilización de algunos cristales, es lo que le proporciona el carácter pumítico de algunas rocas.

\section{Termometría}

Los contenidos elementales de plagioclasa, feldespatos y anfíboles analizados por química mineral, permitieron calcular mediante geotermómetros una temperatura promedio de $618,4^{\circ} \mathrm{C}$ ( $\mathrm{Ti}$ en anfíbol) y $676,0^{\circ} \mathrm{C}$ (anfíbol-plagioclasa) similares a los obtenidos en Peña y Zuluaga (2016) para estas mismas rocas, cuyos valores de temperatura son atribuidos a un proceso hidrotermal posterior a la cristalización. Por otro lado, aunque son temperaturas bajas, para Helz (1973) las temperaturas de cristalización de anfíboles en magmas calcoalcalinos podrían estar entre $950-650^{\circ} \mathrm{C}$.

\section{Composición}

La firma química de las REE muestra un evidente empobrecimiento de las HREE posiblemente atribuido a la cristalización de granate en la fuente del fundido. El rasgo que más resalta en todas las muestras es una prominente anomalía positiva de Eu con promedios de $\mathrm{Eu}_{\mathrm{N}} /\left(\mathrm{Sm}_{\mathrm{N}}{ }^{*} \mathrm{Gd}_{\mathrm{N}}\right)^{1 / 2}$ entre 1,321 para los más bajos y 3,84 para los más altos. La explicación normalmente dada a este comportamiento es el no fraccionamiento de las plagioclasas en las etapas primarias de la diferenciación magmática y si se habla en términos de la fuente, se puede interpretar como un fundido muy rico en feldespatos que ascendió y cristalizó plagioclasas y feldespatos con los altos contenidos de Eu acomodados en la estructura. En este caso y recordando que por el tipo de análisis (trituración de toda la roca sin separación de fenocristales) no se están diferenciando procesos de mezcla, asimilación, etc. El alto contenido de Eu estaría relacionado con la abundancia de feldespatos que acomodan el Eu por el Ca.

\section{Edad del vulcanismo en la zona}

Las dataciones Ar-Ar aquí mostradas reflejan una actividad efusiva (emplazamiento de domos riolíticos) menor a 2,7 y 1,8 Ma. Adicionalmente, la edad reportada para el domo de Iza de 6,01 $\pm 0,03$ Ma demuestra una actividad simultánea con Paipa teniendo presente los resultados para depósitos piroclásticos mostrados en Bernet et al. (2016), lo que reflejaría la continua actividad volcánica en la Cordillera Oriental en este rango de tiempo y la posibilidad que se encuentren en el subsuelo intrusiones que no se manifestaran con un volcanismo en superficie. Adicional a lo anterior, Ortiz y Monsalve (2012) caracterizan unos depósitos volcánicos en el sector de Firavitoba e Iza los cuales están separados de Paipa por una barrera topográfica representada por el anticlinal de Tibasosa-Toledo. Aun así, los autores señalan como posible origen de estos depósitos al volcán de Paipa (área geotérmica de Paipa). Para los depósitos de Firavitoba, Bernet et al. (2016) registran edades de 0,9 y 2,2 Ma, lo que en parte soportaría lo propuesto en Ortiz y Monsalve (2012), pero había que tener presente el hecho de que en Iza no haya existido actividad explosiva más reciente que el emplazamiento de uno de sus domos (6 Ma). Por otro lado, el volcanismo en Paipa muestra una tendencia en la distribución de los depósitos en dirección NE, contraria a la ubicación de los depósitos de Iza.

\section{Evolución magmática}

Las texturas de sobrecrecimiento representadas por núcleos de plagioclasa con coronas de feldespato potásico asociadas principalmente al cuerpo del sector de Quebrada Honda y que se pueden observar petrográficamente para el Alto Los Volcanes, junto con la temporalidad compartida entre estos dos grupos de domos (1,8 Ma) puede reflejar una posible mezcla de magmas que luego se vio reflejada en el evento efusivo que dio origen a los domos del Alto Los Godos de 2,8 Ma. Por otra parte, en el Alto Los Godos, esta textura de sobrecrecimiento es escasa, observándose además, texturas de desequilibrio en los cristales de hornblenda y biotita las cuales reflejarían un cambio en las propiedades del magma. Soportando lo anterior, y como se explica en Pardo (2004), según Hibbard (1995), el cambio de un magma de sódico a potásico se da en un recalentamiento del sistema a una baja tasa 
de nucleación del potasio que crece hasta la pérdida de calor.

\section{Implicaciones de origen}

La discusión generalizada en este punto de la Cordillera Oriental es conocer el origen de este vulcanismo. Existen propuestas como la de Ujueta (1993) quien propone lineamientos NW que cortan el área de estudio, uno de ellos, el lineamiento de Paipa, donde sugiere "fallas profundas que penetran hasta el manto" relacionando estos lineamientos con intrusiones más al sur y con el vulcanismo de Paipa. Por otro lado, estudios geofísicos como el de Gutscher et al. (2000b) demuestran como al norte de Colombia la placa subducida se horizontaliza mientras que al sur permanece más vertical (Figura 14B y 14C). Los autores igualmente manifiestan el papel que podría jugar la placa Caribe en el cambio de ángulo de subducción. Adicional a lo anterior, Gutscher et al. (2000b) exponen la idea de la migración de magmatismo de arco producto de una subducción plana. Aunque atribuyen este efecto a la subducción de una corteza oceánica joven (>10 Ma) advierten que una corteza más antigua podría sufrir un calentamiento dependiendo del tiempo que esta se mantenga a una profundidad constante de al menos 80 $\mathrm{km}$ con temperaturas de $1300^{\circ} \mathrm{C}$ (Figura 14A). Vargas y Mann (2013) publican un trabajo donde propone dos situaciones estructurales para el bloque norte y sur de Colombia, separados por lo que llaman el Caldas Tear. Esta propuesta se basa en análisis de sismos, tomografías y consideraciones geológicas superficiales, donde se muestran una subducción de la placa más horizontal al norte, con un cambio brusco del ángulo y la extensión de la subducción de la placa Nazca al sur, cuya frontera dada por un desgarre (Caldas Tear) se alinea con el Ridge de Sandra, proponiendo en ese trazo una zona de debilidad de la corteza (Figura 14D). Los autores manifiestan la posibilidad de que el vulcanismo activo e inactivo, citando las adakitas del complejo volcánico del Ruiz y el vulcanismo de Paipa, sean producto de la debilidad de la corteza que se traducirían en fallas profundas que permitieron el ascenso del magma.

Teniendo en cuenta todo lo anterior, junto con la firma química (adakítica) de las muestras de este trabajo, y partiendo de todas las consideraciones, especialmente el papel que juega la subducción de la placa Caribe, no se descarta que el vulcanismo de Paipa pueda estar relacionado con una subducción plana cuyo ascenso de magma puede estar facilitado por fallas profundas. Por otro lado, la mineralogía más félsica y química ácida y evolucionada de las muestras de este trabajo, tendrían una relación más directa con otros cuerpos volcánicos y subvolcánicos analizados en el sector de San Diego, también alineado con Paipa y localizado a casi $60 \mathrm{~km}$ al norte del Complejo Volcánico Cerro Bravo - Cerro Machín (Figura 14B) (Rueda-Gutiérrez y Rodríguez, 2016; Monsalve, 2015; Borrero et al., 2017; Monsalve et al., 2019; Murcia et al., 2019; Sánchez-Torres et al., 2019), las cuales difieren de las firmas comúnmente andesíticas con predominio de plagioclasa + piroxeno y que son típicas de las rocas volcánicas del bloque norte de la Cordillera Central.

\section{Historia eruptiva}

En este trabajo, y en base solo en la distribución espacial de los depósitos mostrados en Cepeda y Pardo (2004) y las edades de los productos eruptivos, trazas de fisión en Bernet et al. (2016) y Ar-Ar de este trabajo, así como evidencias geofísicas aportadas por otros trabajos, se plantea la siguiente secuencia de eventos: la actividad volcánica comenzó posiblemente en el sector del Alto Los Volcanes con erupciones explosivas hace 9,9 y $6,9 \mathrm{Ma}$ (edades en Bernet et al., 2016). Los depósitos eruptivos se distribuyeron en dirección noreste, llegando hasta el Pantano de Vargas (noreste del área de estudio). Hace 6 Ma la actividad del volcán de Paipa era simultánea al emplazamiento de al menos uno de los domos del sector de Iza. Erupciones sucesivas ocurrieron en la zona durante aproximadamente $4 \mathrm{Ma}$, luego, a los 2,8 Ma ocurre el ascenso de los domos del sector del Alto Los Godos facilitado posiblemente por el carácter distensivo de las fallas profundas de Cerro Plateado y Agua Tibia. Estos domos se exponen en superficie y cortan la sucesión de depósitos volcánicos en algunos sectores. Las activad efusiva resurge hace 1,8-1,7 Ma con el emplazamiento de los domos del Alto Los Volcanes y Quebrada Honda, promovido por el ascenso de magma desde las fallas Paipa - Iza y Cerro Plateado. Luego del emplazamiento de los cuerpos dómicos, resurge la actividad explosiva dando origen a los flujos de bloques y cenizas especialmente en el sector del Alto Los Volcanes, aunque nuevos afloramientos en el Alto Los Godos dejan ver depósitos con grandes bloques volcánicos en la base de los domos. Esta última actividad es seguramente la responsable de la forma irregular y con señales de colapso gravitacional de los cuerpos dómicos en el sector del Alto Los Volcanes. 


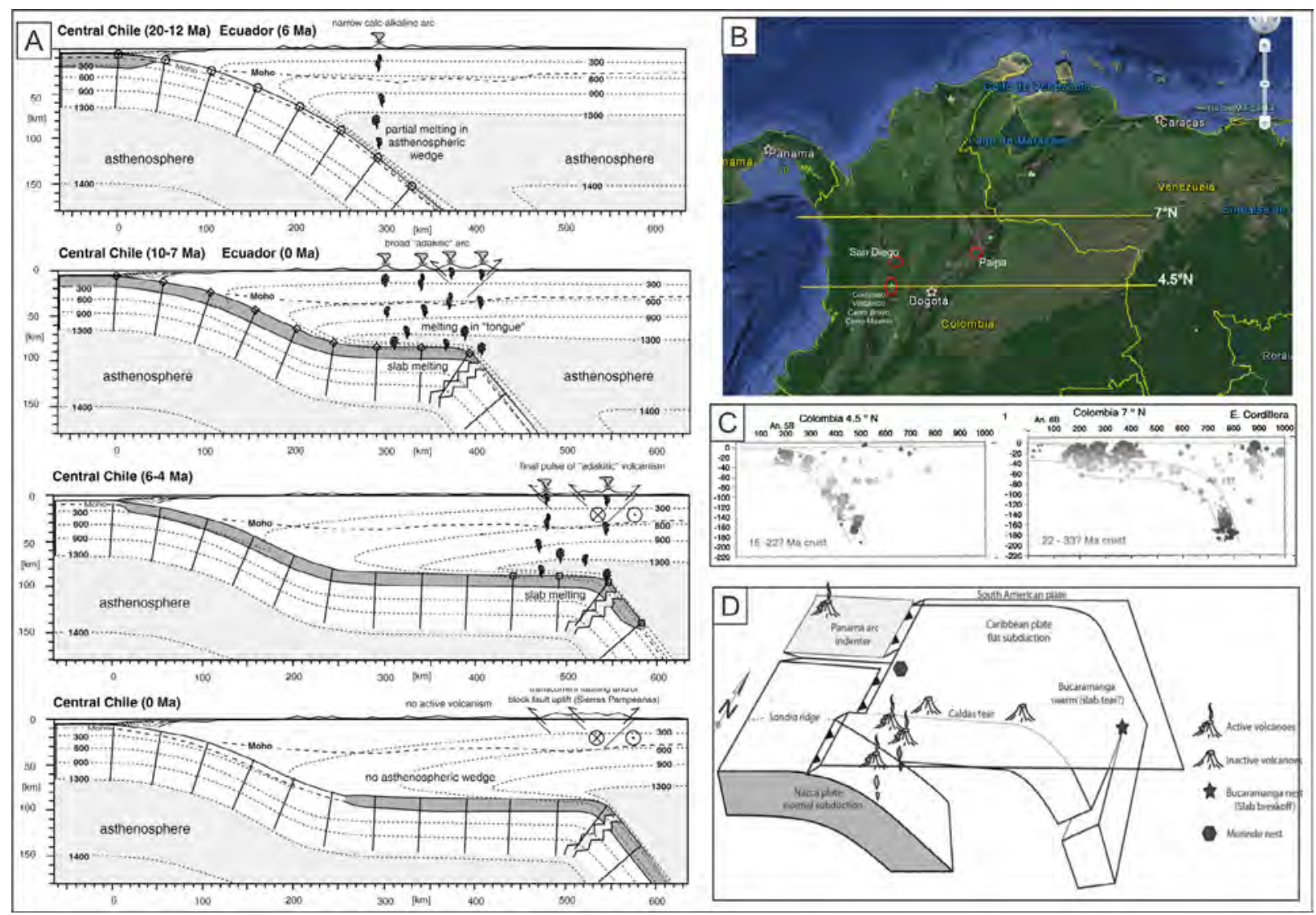

Figura 14. Evidencias geofísicas y representaciones esquemáticas del estilo de subducción y su posible asociación al magmatismo de la Cordillera Oriental. A. Representación esquemática de las etapas de una subducción plana mostrada en Gutscher et al. (2000a). B. Trazo de los perfiles mostrado en C. C. Secciones esquemáticas sísmicas a los $7^{\circ} \mathrm{N} \mathrm{y} 4,5^{\circ} \mathrm{N}$ mostradas en Gutscher et al. (2000b). D. Modelo esquemático 3D de Vargas y Mann (2013) mostrando la geometría del Caldas Tear y el ridge de Sandra como zona de debilidad.

\section{Implicaciones en el estudio del sistema geotérmico de Paipa}

Es evidente que la edad de los cuerpos dómicos corresponden a un evento relativamente antiguo (2,7-1,8 Ma), aunque dataciones mediante huellas de fisión ilustradas en Bernet et al. (2016) para algunos depósitos volcánicos, representan edades más jóvenes de hasta $1 \mathrm{Ma}$, existiendo la posibilidad que, junto con evidencias geofísicas y rasgos geomorfológicos, puedan existir intrusiones (recientes y/o de mayor volumen) en el área geotérmica, pero que no se expresan en superficie, siendo estas manifestaciones magmáticas las responsables de proporcionar el calor necesario para el calentamiento de las aguas tal como está expuesto en Alfaro et al. (2017). Por otro lado, el vulcanismo de Iza localizado a $17 \mathrm{~km}$ al SW de Paipa y cuya edad en uno de sus domos dio $6 \mathrm{Ma}$, puede ser evidencia de la existencia cámaras magmáticas, sin expresiones superficiales, en medio de estos dos focos. El tipo de alteración más común en algunos de los cuerpos dómicos es del tipo argílica junto con la presencia de vidrio en algunas muestras, pero generalmente se ven inalterados, pero con un importante intemperismo. Por otro lado, y como se muestra en Alfaro (2005), líticos metamórficos localizados dentro de los depósitos volcánicos cerca al sector de Olitas muestran una importante alteración, lo cual es interpretado como un sistema de alta temperatura que se encuentra en profundidad, cubierto por los depósitos volcánicos y niveles lodosos y arenosos de la secuencia sedimentaria que se expone en la zona de estudio.

\section{Conclusiones}

Con la cartografía de los domos y la caracterización de estos, se amplió el conocimiento de los productos 
eruptivos del volcán de Paipa y se puede reevaluar el modelo de caldera volcánica propuesto para el vulcanismo de este sector de la Cordillera Oriental.

Los domos presentan petrográficamente cristales de feldespato potásico, plagioclasa, biotita, hornblenda y cantidades variables de vidrio para los cuerpos del sector Alto Los Volcanes y Quebrada Honda. Para los cuerpos del Alto Los Godos predomina el feldespato potásico, plagioclasa, hornblenda y vidrio. La petrografía y química mineral permiten establecer un cambio en la composición del magma (dada la mezcla con un nuevo pulso) dando origen a las texturas de sobrecrecimiento representadas por núcleos de plagioclasas (albita) con coranas de feldespatos potásicos (anortoclasa).

Los resultados reafirmaron el carácter riolítico y evolucionado de las intrusiones. Químicamente se clasifican por contenido de $\mathrm{SiO}_{2}$ y $\mathrm{Na}_{2} \mathrm{O}-\mathrm{K}_{2} \mathrm{O}$ como traquitas y riolitas, de afinidad calcoalcalina con firma química de arco. Según la firma química de elementos menores se observa un enriquecimiento de LREE respecto a las HREE con una evidente anomalía positiva de Eu para todas las muestras.

La microtermometría permite definir temperaturas entre 618 y $675,9^{\circ} \mathrm{C}$ posiblemente asociadas a procesos hidrotermales.

Las dataciones revelaron actividad efusiva en el volcán de Paipa hace 1,8 y 2,7 Ma que dieron origen al complejo de domos del Alto Los Volcanes y Alto Los Godos respectivamente. La edad reportada en el domo de Iza es de 6 Ma. Lo anterior, y teniendo presente dataciones de los depósitos volcánicos de Paipa y Firavitoba, demuestra una actividad simultánea de estos centros eruptivos (Paipa e Iza).

Aunque la geocronología muestra a los cuerpos dómicos con una edad de entre 1,8 a 2,7 Ma, no se debe descartar que las geoformas dómicas sin expresión litológica superficial, pero que se pueden inferir a partir de anomalías geofísicas, puedan ser intrusiones más recientes. En tal sentido, el aporte de calor que estos cuerpos puedan dar al sistema geotérmico podría sería de gran importancia.

\section{Agradecimientos}

Se agradece al Servicio Geológico Colombiano dado que la realización de este artículo se dio dentro del marco de los estudios realizados por el Grupo de
Investigación y Exploración de Recursos Geotérmicos; se agradece a la geóloga Gina Rodríguez quien hizo parte de una de las fases de campo. Gracias a todos los profesionales y técnicos del laboratorio químico del SGC, así como a los miembros del grupo de Investigación y Exploración de Recursos Geotérmicos que hicieron parte de este trabajo de una u otra forma.

\section{Referencias}

Alfaro, C. (2001). Geoquímica de las fuentes termales del área de Paipa-Iza. Informe Técnico, INGEOMINAS, Bogotá, Colombia.

Alfaro, C. (2002). Geoquímica del sistema geotérmico de Paipa. Informe Técnico, INGEOMINAS, Bogotá, Colombia.

Alfaro, C. (2005). Alteración hidrotermal en el sistema geotérmico de Paipa. Informe Técnico, INGEOMINAS, Bogotá, Colombia.

Alfaro, C.; Matiz, J.C.; Rueda, J.; Rodríguez, G.; González, C.; Beltrán, M.; Rodríguez, G.; Malo, J. (2017). Actualización del modelo conceptual del área geotérmica de Paipa. Informe Técnico, Servicio Geológico Colombiano, Bogotá, Colombia.

Beltrán, M.A. (2015). Interpretación de anomalías magnetométricas y gravimétricas en el área geotérmica de Paipa. Informe Técnico, Servicio Geológico Colombiano, Bogotá, Colombia.

Bernet, M.; Urueña, C.; Amaya, S.; Peña, M. (2016). New thermo and geochronological constraints on the Pliocene-Pleistocene eruption history of the Paipa-Iza volcanic complex, Eastern Cordillera, Colombia. Journal of Volcanology and Geothermal Research, 327, 299-309. https:// doi.org/10.1016/j.jvolgeores.2016.08.013

Blundy, J.; Holland, T. (1990). Calcic amphibole equilibria and a new amphibole-plagioclase geothermometer. Contributions to Mineralogy and Petrology, 104(2), 208-224. https://doi. org/10.1007/BF00306444

Borrero, C.; Murcia, H.; Agustín-Flores, J.; Arboleda, M.T.; Giraldo, A.M. (2017). Pyroclastic deposits of San Diego maar, central Colombia: an example of a silicic magma-related monogenetic eruption in a hard substrate. Geological Society, London, 
Special Publications, 446, 361-374. https://doi. org/10.1144/SP446.10

Cepeda, H.; Pardo, N. (2004). Vulcanismo en Paipa. Informe Técnico, INGEOMINAS, Bogotá, Colombia.

CHEC. (1983). Investigación Geotérmica Macizo Volcánico del Ruiz. Fase II, etapa A, Vol-III, Parte A, Geovulcanología, Manizales, Central Hidroeléctrica de Caldas.

Defant, M.; Drummond, M. (1990). Derivation of some modern arc magmas by melting of young subducted lithosphere. Nature, 347(6294), 662665. https://doi.org/10.1038/347662a0

ENUSA-IAN. (1979). Reporte Contrato I. 76 p. Empresa Nacional del Uranio S.A. - Instituto de Asuntos Nucleares, Bogotá, Colombia.

Ferreira, P.; Hernández, R. (1988). Evaluación geotérmica en el área de Paipa basada en técnicas isotópicas, geoquímica y aspectos estructurales. Tesis, Universidad Nacional de Colombia, Bogotá, Colombia.

Garzón, T. (2003). Geoquímica y potencial minero asociado a cuerpos volcánicos en la región de Paipa, departamento de Boyacá, Colombia. Tesis, Universidad Nacional de Colombia, Bogotá, Colombia.

González, L.; Vásquez, L.; Muñoz, R.; Gomes, H.; Parrado, G.; Vargas, S. (2008). Exploración de Uranio en Paipa, Iza, Pesca, Chivata (Boyacá). Informe técnico, INGEOMINAS, Bogotá, Colombia.

Gutscher, M.A.; Maury, R.; Eissen, J.P.; Bourdon, E. (2000a). Can slab melting be caused by flat subduction? Geology, 28(6), 535-538. https://doi. org/10.1130/0091-7613(2000)28<535:CSMBCB $>2.0 . \mathrm{CO} ; 2$

Gutscher, M.A.; Spakman, W.; Bijwaard, H.; Engdahl, R. (2000b). Geodynamics of flat subduction: Seismicity and tomographic constraints the Andean margin. Tectonics, 19(5), 814-833. https://doi.org/10.1029/1999TC001152
Hammarstrom, J.; Zen, E. (1986). Aluminium in hornblende: an empirical igneous geobarometer. American Mineralogist, 71(11-12), 1297-1313.

Hernández, G.; Osorio, O. (1990). Geología, análisis petrográfico y químico de las rocas volcánicas del suroriente de Paipa (Boyacá-Colombia). Tesis, Universidad Nacional de Colombia, Bogotá, Colombia.

Helz, R. (1973). Phase relations of basalts in their melting range at $\mathrm{P}_{\mathrm{H} 2 \mathrm{O}}=5 \mathrm{~kb}$ as a function of oxygen fugacity: Part I. Mafic phases. Journal of Petrology, 14(2), 249-302. https://doi. org/10.1093/petrology/14.2.249

Hibbard, M.J. (1995). Petrography to petrogenesis. Prentice Hall.

Hollister, L.; Grissom, G.; Peters, E.; Stowell, H.; Sisson. V. (1987). Confirmation of the empirical correlation of $\mathrm{Al}$ in hornblende with pressure of solidification of calc-alkaline plutons. American Mineralogist, 72(3-4), 231-239.

Johnson, M.; Rutherford. M. (1989). Experimental calibration of the aluminum-in-hornblende geobarometer with application to Long Valley caldera (California) volcanic rocks. Geology, 17(9), 837-841. https://doi.org/10.1130/00917613(1989)017<0837:ECOTAI>2.3.CO;2

Leake, B.; Woolley, A.; Arps, C.; Birch, W.; Gilbert, M.; Grice, J.; Hawthorne, F.; Kato, A.; Kisch, H.; Krivovichev, V.; Linthout, K.; Laird, J.; Mandarino, J.; Maresch, W.; Nickel, E.; Rock, N.; Schumacher, J.; Smith, D.; Stephenson, N.; Ungaretti, L.; Whittaker, E.; Youzhi, G. (1997). Nomenclature of amphiboles: report of the subcommittee on amphiboles of the International Mineralogical Association, commission on new minerals and mineral names. The Canadian Mineralogist, 35(1), 219-246.

Le Bas, M.J.; Le Maitre, R.W.; Streckeisen, A.; Zanettin, B. (1986). A chemical classification of volcanic rocks based on the total alkali-silica diagram. Journal of Petrology, 27(3), 745-750. https://doi.org/10.1093/petrology/27.3.745 
Martin, H. (1999). Adakitic magmas: modern analogues of Archean granitoids. Lithos, 46(3), 411-429. https://doi.org/10.1016/S0024-4937(98)00076-0

Martínez, A. (1989). Geologie de la región d’Iza, Boyaca. Cordillere orientale de Colombie. Thèse, Universite de Lausanne, Suisse.

McDonough, W.F.; Sun, S.; Ringwood, A.E.; Jagoutz, E.; Hofmann, A.W. (1992). Potassium, rubidium, and cesium in the Earth and Moon and the evolution of the mantle of the Earth. Geochimica et Cosmochimica Acta, 56(3), 1001-1012. https:// doi.org/10.1016/0016-7037(92)90043-I

Monsalve, M. (2015). Informe de avance del volcanismo en el área geotérmica de San Diego (Caldas). Informe de Avance, Servicio Geológico Colombiano, Bogotá, Colombia.

Monsalve, M.L.; Ortiz, I.D.; Norini, G. (2019). El Escondido, a newly identified silicic Quaternary volcano in the NE region of the northern volcanic segment (Central Cordillera of Colombia). Journal of Volcanology and Geothermal Research, 383, 47-62. https://doi.org/10.1016/j.jvolgeores.2017.12.010

Monsalve, M.L.; Rojas, N.R.; Velandia, F.P.; Pintor, I.; Martínez, L.F. (2011). Caracterización geológica del cuerpo volcánico de Iza, Boyacá, Colombia. Boletín de Geología, 33(1), 117-130.

Murcia, H.; Borrero, C.; Németh, K. (2019). Overview and plumbing system implications of monogenetic volcanism in the northernmost Andes' volcanic province. Journal Volcanology and Geothermal Research, 383, 77-87. https://doi.org/10.1016/j.jvolgeores.2018.06.013

Nakamura, N. (1974). Determination of REE, Ba, Mg, $\mathrm{Na}$, and $\mathrm{K}$ in carbonaceos and ordinary chondrites. Geochemical et Cosmochimical Acta, 38(5), 757-775. https://doi.org/10.1016/0016-7037(74)90149-5

Navia, A.; Barriga, A. (1929). Informe sobre las aguas termomedicinales de Paipa, Colombia. Imprenta Nacional. 76 p. Bogotá.

OLADE; GEOTÉRMICA ITALIANA; ICEL; CONTECOL. (1982). Estudio de reconocimiento de los recursos geotérmicos de la república de Colombia. 7 volúmenes. Pisa: Organización
Latinoamericana de Energía, Geotérmica Italiana Srl, Instituto Colombiano de Energía Electrica, Contecol ltda.

Ortiz, I.; Monsalve, M. (2012). Nuevos aportes al conocimiento del volcanismo en el área geotérmica de Paipa-Iza. Informe Interno, Servicio Geológico Colombiano, Bogotá, Colombia.

Otten, M. (1984). The origin of brown hornblende in the Artfjället gabbro and dolerites. Contributions to Mineralogy and Petrology, 86(2), 189-199. https://doi.org/10.1007/BF00381846

Pardo, N. (2004). Estratigrafía de las vulcanitas asociadas al Volcán de Paipa, municipios de Paipa y Tuta. Tesis, Universidad Nacional de Colombia, Bogotá, Colombia.

Pearce, J.A.; Harris, N.B.W.; Tindle, A.G. (1984). Trace element discrimination diagrams for the tectonic interpretation of granitic rocks. Journal of Petrology, 25(4), 956-983. https://doi.org/10.1093/petrology/25.4.956

Peccerillo, A.; Taylor, S.R. (1976). Geochemistry of eocene calc-alkaline volcanic rocks from the Kastamonu area, Northern Turkey. Contributions to Mineralogy and Petrology, 58(1), 63-81. https://doi.org/10.1007/BF00384745

Peña, Y.; Zuluaga, C. (2016). Evaluación petrológica de las rocas de Paipa, Boyacá. Tesis, Universidad Nacional de Colombia, Bogotá, Colombia.

Renzoni, G.; Rosas, H. (1967). Geología de la Plancha 171, Duitama. Mapa Geológico. Escala 1:100.000. INGEOMINAS.

Renzoni, G.; Rosas, H. (1976). Geología de las Planchas 171 Duitama y 211 Tauramena, cuadrángulos K-13 y J-12, escala 1:100.000. Boletín Geológico, 24(2), $1-48$.

Rodríguez, G.; Alfaro, C. (2015). Caracterización de núcleos de perforación en las zonas de El Durazno, Paipa y criptodomo de Iza. Informe técnico, Servicio Geológico Colombiano, Bogotá, Colombia.

Rueda-Gutiérrez, J. (2017). Cartografía de los cuerpos dómicos del área geotérmica de Paipa. Informe técnico, Servicio Geológico Colombiano, Bogotá, Colombia. 
Rueda-Gutiérrez, J.; Rodríguez, G. (2016). Geología del área geotérmica de San Diego. Informe Técnico, Servicio Geológico Colombiano, Bogotá, Colombia.

Sánchez-Torres, L.; Toro, A.; Murcia, H.; Borrero, C.; Delgado, R.; Gómez-Arango, J. (2019). El Escondido tuff cone (38 ka): a hidden history of monogenetic eruptions in the northernmost volcanic chain in the Colombian Andes. Bulletin of Volcanology, 81(12). https://doi.org/10.1007/s00445-019-1337-2

Sarmiento P. (1941). Geología de la región PaipaDuitama. Boletín del Servicio Geológico Nacional. Informe $\mathrm{N}^{\mathrm{o}}$ 353. Servicio Geológico Nacional. Bogotá, Colombia.

Schmidt, M.W. (1992). Amphibole composition in tonalite as a function of pressure: an experimental calibration of the Al-inhornblende-barometer. Contributions to Mineralogy and Petrology, 110(2-3), 304-310. https://doi.org/10.1007/BF00310745

Suárez, J. (2016). Mecanismos de transporte y acumulación durante las erupciones piroclásticas más explosivas, registradas al sur de Paipa, en la Cordillera Oriental de Colombia. Tesis, Universidad de los Andes, Bogotá, Colombia.

Ujueta, G. (1993). Lineamientos Muzo, Tunja y Paipa en los Departamentos de Boyacá y Casanare, Colombia. Geología Colombiana, 18, 65-73.

Vargas, C.; Mann, P. (2013). Tearing and breaking off of subducted slabs as the result of collision of the Panama Arc-Indenter with Northwestern South America. Bulletin of the Seismological Society of America, 103(3), 2025-2046. https://doi.org/10.1785/0120120328

Velandia, F. (2003). Cartografía geológica y estructural sector sur del municipio de Paipa. Informe técnico, INGEOMINAS, Bogotá, Colombia.

Winchester, J.A.; Floyd, P.A. (1977). Geochemical discrimination of different magma series and their differentiation products using immobile elements. Chemical Geology, 20, 325-343. https://doi.org/10.1016/0009-2541(77)90057-2

Trabajo recibido: febrero 13 de 2019 Trabajo aceptado: julio 23 de 2020 